ZRC SAZU, UMETNOSTNOZGODOVINSKI INŠTITUT FRANCETA STELETA

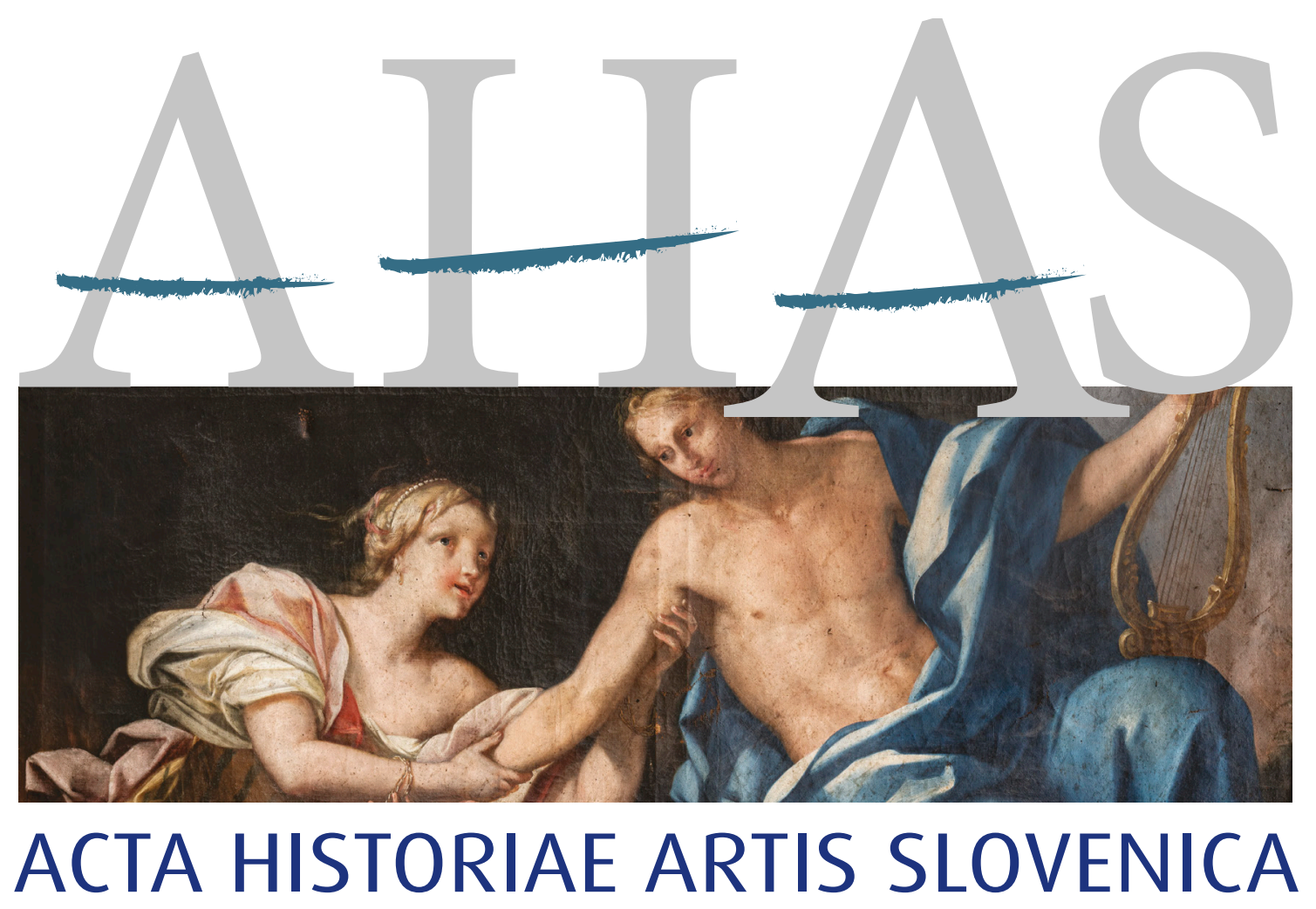

Frančišek Karel Remb in slikarstvo

v habsburških dednih deželah okrog leta 1700

Franz Carl Remp and Painting in the Habsburg Hereditary Lands around 1700

Franz Carl Remp und die Malerei in den habsburgischen Erblanden um 1700

$$
26 \mid 2 \cdot 2021
$$




\section{ACTA HISTORIAE ARTIS SLOVENICA $26 \mid 2 \cdot 2021$}

Frančišek Karel Remb in slikarstvo v habsburških dednih deželah okrog leta 1700

Franz Carl Remp and Painting in the Habsburg Hereditary Lands around 1700

Franz Carl Remp und die Malerei in den habsburgischen Erblanden um 1700 
Acta historiae artis Slovenica, 26/2, 2021

Frančišek Karel Remb in slikarstvo v habsburških dednih deželah okrog leta 1700

Franz Carl Remp and Painting in the Habsburg Hereditary Lands around 1700

Franz Carl Remp und die Malerei in den habsburgischen Erblanden um 1700

Znanstvena revija za umetnostno zgodovino / Scholarly Journal for Art History

ISSN 1408-0419 (tiskana izdaja / print edition) ISSN 2536-4200 (spletna izdaja / web edition)

ISBN 978-961-05-0568-6

Izdajatelj / Issued by

ZRC SAZU, Umetnostnozgodovinski inštitut Franceta Steleta /

ZRC SAZU, France Stele Institute of Art History

Založnik / Publisher

Založba ZRC

Urednika / Edited by

Edgar Lein, Polona Vidmar

Uredniški odbor / Editorial board

Renata Komić Marn, Tina Košak, Katarina Mohar, Mija Oter Gorenčič, Blaž Resman, Helena Seražin

Mednarodni svetovalni odbor / International advisory board

Günter Brucher (Salzburg), Ana María Fernández García (Oviedo), Hellmut Lorenz (Wien),

Milan Pelc (Zagreb), Sergio Tavano (Gorizia-Trieste), Barbara Wisch (New York)

Lektoriranje / Language editing

Oliver Currie, Manuela Dajnko, Andrea Leskovec

Prevodi / Translations

Alan Harvey Cook, Blaž Resman, Nika Vaupotič, Polona Vidmar

Celostni strokovni in jezikovni pregled / Expert and language editing

Blaž Resman

Oblikovna zasnova in prelom / Design and layout

Andrej Furlan

Naslov uredništva / Editorial office address

Acta historiae artis Slovenica

Novi trg 2, p. p. 306, SI -1001 Ljubljana, Slovenija

ahas@zrc-sazu.si; https://ojs.zrc-sazu.si/ahas

Revija je indeksirana v / Journal is indexed in

Scopus, ERIH PLUS, EBSCO Publishing, IBZ, BHA

Letna naročnina / Annual subscription: $35 €$

Posamezna enojna številka / Single issue: $25 €$

Letna naročnina za študente in dijake: $25 €$

Letna naročnina za tujino in ustanove / Annual subscription outside Slovenia, institutions: $48 €$

Naročila sprejema / For orders contact

Založba ZRC

Novi trg 2, p. p. 306, SI-1001, Slovenija

E-pošta / E-mail: zalozba@zrc-sazu.si

AHAS izhaja s podporo Javne agencije za raziskovalno dejavnost Republike Slovenije.

AHAS is published with the support of the Slovenian Research Agency.

(c) 2021, ZRC SAZU, Umetnostnozgodovinski inštitut Franceta Steleta, Založba ZRC, Ljubljana Tisk / Printed by Collegium Graphicum d.o.o., Ljubljana

Naklada / Print run: 400 


\section{VSEBINA \\ Contents}

Edgar Lein, Polona Vidmar

Frančišek Karel Remb in slikarstvo v habsburških dednih deželah okrog leta 1700. Predgovor ...........................5

Franz Carl Remp and Painting in the Habsburg Hereditary Lands around 1700. Preface .....................................7

Franz Carl Remp und die Malerei in den habsburgischen Erblanden um 1700. Vorwort .....................................9

\section{DISSERTATIONES}

Karin Požin

Remp's Ceiling Paintings in the Palais Attems in Graz. From Reproductive Prints to Frescoes

Rembove stropne poslikave v graški palači Attems. Od grafičnih predlog do fresk ...13

Georg Lechner

Franz Carl Remp zwischen Graz und Wien 31

Frančišek Karel Remb med Gradcem in Dunajem 48

Edgar Lein

Preis und Wert der Malerei um 1700. Zu den Kosten von Gemälden in der Steiermark 51

Cena in vrednost slik okrog leta 1700. O stroških za slike na Štajerskem

Renata Komić Marn

Zaplemba - prenos - distribucija. Slike grofa Attemsa iz gradu Slovenska Bistrica $v$ slovenskih javnih zbirkah

Confiscation - Transfer - Distribution. Count Attems' Paintings from

Slovenska Bistrica Castle in Slovenian Public Collections

Polona Vidmar

Emblematische Gratulationsschriften, Stammbäume und Porträts

von Dominik Franz Calin von Marienberg für das Haus Habsburg.

Emblematična voščila, rodovniki in portreti Dominika Frančiška Kalina

von Marienberga za Habsburžane

Ulrich Becker

Weltgeschichte im Wimmelbild. Stephan Kessler und der Entsatz von Wien 1683.

Svetovna zgodovina na »mrgoleči sliki«. Stephan Kessler in Rešitev Dunaja leta 1683 
Andreas Gamerith

Zeit des Experiments. Die Galleria maior des Stiftes Zwettl als Beispiel

für seicenteske Wandmalerei in Niederösterreich.

Čas eksperimentiranja. Galleria maior v samostanu Zwettl

kot primer stenskega slikarstva 17. stoletja v Spodnji Avstriji

\section{Martin Mádl}

The Patterns of the Transformation in Central European Ceiling Painting

around 1700 and Franz Carl Remp in Brežice Castle.

Vzorci transformacije v srednjeevropskem stropnem slikarstvu okrog leta 1700

in Frančišek Karel Remb v brežiškem gradu 


\section{Predgovor}

\section{FranČIŠEK KAREL REMB IN SLIKARSTVO V HABSBURŠKIH DEDNIH DEŽELAH OKROG LETA 1700}

Kljub razmeroma številnim slikam je ostal opus v Radovljici rojenega ter v Gradcu in na Dunaju delujočega slikarja Frančiška Karla Remba (1675-1718) široki javnosti doslej večinoma neznan. Prva in zaenkrat edina razstava Rembovih del je bila od 26. oktobra 1973 do 19. maja 1974 na ogled v Spodnjem Belvederu na Dunaju ter junija 1974 v vogalni sobi Stare galerije muzeja Joanneum v graški Neutorgasse. Razstavni katalog z naslovom Der Barockmaler Franz Carl Remp 1674-1718 vsebuje sedem strani obsegajoč uvod v umetnikovo življenje in delo, kataložni del z dvajsetimi enotami, časovnico in seznam literature.

Georg Lechner se je s Frančiškom Karlom Rembom ukvarjal v okviru svoje leta 2010 na Dunaju obranjene doktorske disertacije. Ko je spomladi 2018 Lechner opozoril, da se jeseni bliža tristota obletnica Rembove smrti, vendar ni niti na Dunaju niti v Gradcu načrtovana kakšna razstava slikarjevih del, smo se odločili za organizacijo simpozija, ki je pod naslovom Slikarji in naročniki. Frančišek Karel Remb in slikarstvo na Štajerskem okrog 1700 potekal 23. novembra 2018 v Laterneng'wölb dvorca Eggenberg. Naslednji dan so si udeleženci pod vodstvom Georga Lechnerja ogledali palačo Attems in pod vodstvom Paula Schusterja reprezentativne prostore dvorca Eggenberg. Simpozij so podprli univerzi v Gradcu in Mariboru ter Znanstvenoraziskovalni center Slovenske akademije znanosti in umetnosti, Umetnostnozgodovinski inštitut Franceta Steleta. Bil je del bilateralnega projekta BI SLO-AT/16-17-18: Umetnostni naročniki kot nosilci deželne identitete. Vloga in pomen naročnikov za gradnjo in opremo plemiških rezidenc in romarskih središč na Štajerskem, ki sta ga financirala Javna agencija za raziskovalno dejavnost Republike Slovenije in Österreichischer Austauschdienst, ter temeljnega raziskovalnega projekta J6-7410: Umetnostna reprezentacija plemstva. Naročništvo na Štajerskem $v$ zgodnjem novem veku (2016-2018), ki ga je financirala Javna agencija za raziskovalno dejavnost Republike Slovenije.

Simpozij so otvorili Georg Lechner s temeljnim prispevkom o Frančišku Karlu Rembu med Gradcem in Dunajem (Franz Carl Remp zwischen Graz und Wien), Christine Rabensteiner, ki je predstavila dela priseljenih in na Štajerskem rojenih baročnih slikarjev v depojih graške Stare galerije (Werke immigrierter und gebürtiger steirischer Barockmaler. Ein Blick in das Depot der Alten Galerie), ter Karin Požin s študijo o Rembovih stropnih poslikavah v palači Attems v Gradcu in likovnih virih zanje (Case Study of Remp's Ceiling Paintings in Palais Attems in Graz. From Reproductive Prints to Frescoes). V drugem delu je Edgar Lein predstavil ceno in vrednost slikarskih del okrog 1700 (Preis und Wert der Malerei um 1700), Tina Košak pa je na podlagi virov v mestnem arhivu v Antwerpnu raziskala trgovce $\mathrm{z}$ umetninami iz družine Forchondt in njihove štajerske stranke (The Forchondt Art Dealers and their Styrian Clients. Excerpts from the Antwerp City Archives). Renata Komić Marn je analizirala portrete Eleonore Marije Rozalije kneginje Eggenberg (The Portraits of Eleonora Maria Rosalia Princess of Eggenberg), Polona Vidmar pa je predstavila slikane genealogije štajerskega plemstva okrog leta 1700 (Gemalte Genealogien des steirischen Adels um 1700). Meje historične Štajerske so s svojimi referati presegli Ulrich Becker, ki je Stephanu Kesslerju pripisal upodobitvi Rešitve 
Dunaja leta 1683 (Weltgeschichte als Wimmelbild. Stephan Kessler und der Entsatz von Wien 1683), Andreas Gamerith, ki se je ukvarjal s stropnimi poslikavami pred Trogerjem oziroma okrog leta $1700 \mathrm{v}$ samostanih Zwettl in Altenburg (Vor Troger. Aspekte der Wandmalerei um 1700 am Beispiel der Klöster Zwettl und Altenburg), ter Martin Mádl z izčrpnim predavanjem o češkem stropnem slikarstvu okoli 1700 („So ist nun ... der Pracht im Bauen so hoch gestiegen ..... Profane Ceiling Painting in Bohemia around 1700).

Udeleženci simpozija so svoje referate pripravili za tisk ali pa so prispevali nova raziskovalna spoznanja, ki jih v Acta historiae artis Slovenica objavljamo pod naslovom Frančišek Karel Remb in slikarstvo v habsburških dednih deželah okrog leta 1700. Prispevka Karin Požin in Georga Lechnerja poglabljata vedenje o Rembovih stenskih poslikavah v palači Attems in o delih, ki jih je ustvaril po selitvi na Dunaj. Nekatere Rembove oljne slike so obravnavane tudi v prispevkih Edgarja Leina, ki se je posvetil stroškom za slike na Štajerskem, ter Renate Komić Marn, ki je raziskala slike iz Attemsove zbirke v Slovenski Bistrici v slovenskih javnih zbirkah. Slikarstvo zadnjih desetletij 17. stoletja je tema prispevkov Polone Vidmar, ki se je posvetila delom Dominika Frančiška Kalina von Marienberga za Habsburžane, in Ulricha Beckerja, ki je upodobitvi Rešitve Dunaja atribuiral tirolskemu slikarju Stephanu Kesslerju. Andreas Gamerith je Gallerio maior v samostanu Zwettl predstavil kot eksperiment v stropnem slikarstvu poznega 17. stoletja v Spodnji Avstriji, zvezek pa zaključuje prispevek Martina Mádla, ki se je posvetil transformaciji srednjeevropskega slikarstva okrog leta 1700 in pomembnim zgledom zanjo.

Upava, da bodo raznoliki prispevki in številne upodobitve spodbudili nadaljnje raziskovanje baročnega slikarstva. 


\section{Preface}

\section{Franz Carl Remp and Painting in THE HABSbURg Hereditary LANDS AROUND 1700}

The oeuvre of Radovljica born painter Franz Carl Remp (1675-1718) who worked in Graz and Vienna is little-known to the wider public despite his relatively numerous paintings. The first and only exhibition of Remp's works up to now was held from 26 October 1973 to 19 May 1974 at the Lower Belvedere in Vienna, and in the corner room of the present-day Universalmuseum Joanneum's Alte Galerie in Neutorgasse in Graz in June 1974. The exhibition catalogue entitled Der Barockmaler Franz Carl Remp 1674-1718 includes a seven-page introduction to the artist's life and work, a catalogue comprising twenty units, a chronology, and list of sources.

Georg Lechner researched Franz Carl Remp in his PhD thesis, which he defended 2010 in Vienna. In the spring of 2018, Lechner drew attention to the fact that the $300^{\text {th }}$ anniversary of the painter's death would occur in the autumn of the same year, and that neither Vienna nor Graz planned to commemorate the anniversary with an exhibition of the Baroque painter's works. We therefore decided to organize a conference entitled Painters and Patrons. Franz Carl Remp and Painting in Styria around 1700 that was held on 23 November 2018 at the Laterneng'wölb in the Eggenberg Castle. The following day the participants went on a tour of the Palais Attems, guided by Georg Lechner, as well as a tour of Eggenberg Castle's monumental rooms guided by Paul Schuster. The conference was supported by the Universities of Graz and Maribor, and the Research Centre of the Slovenian Academy of Sciences and Arts, the France Stele Institute of Art History. It formed part of the bilateral project BI SLO-AT/16-17-18: Art Patrons as Carriers of Province's Identity. The Role and Significance of Commissioners of Architectures and Furnishings of Aristocratic Residences and Pilgrimage Sites in Styria, which was financed by the Slovenian Research Agency and the Österreichischer Austauschdienst, and the research project J6-7410: Visual Representations of the Nobility. Early Modern Art Patronage in the Styria Province (2016-2018), financed by the Slovenian Research Agency.

The conference opened with Georg Lechner's general and foundational contribution - Franz Carl Remp between Graz and Vienna (Franz Carl Remp zwischen Graz und Wien) - followed by Christine Rabensteiner, who presented the works of immigrant and Styria-born Baroque painters in storage in the Alte Galerie in Graz (Werke immigrierter und gebürtiger steirischer Barockmaler. Ein Blick in das Depot der Alten Galerie), and Karin Požin with her study of Remp's ceiling paintings in Palais Attems in Graz and their sources (Case Study of Remp's Ceiling Paintings in Palais Attems in Graz. From Reproductive Prints to Frescoes). In the second part of the conference there were papers on the wider context and Styrian art of the period. Edgar Lein gave a spech on the cost and value of paintings around 1700 (Preis und Wert der Malerei um 1700). Tina Košak presented a study of the art dealers from the Forchondt family and their Styrian clients based on sources in the Antwerp city archives (The Forchondt Art Dealers and their Styrian Clients. Excerpts from the Antwerp City Archives). Renata Komić Marn analysed the portraits of Eleonora Maria Rosalia Princess of Eggenberg (The Portraits of Eleonora Maria Rosalia Princess of Eggenberg), and Polona Vidmar presented the painted genealogies of Styrian nobility around 1700 (Gemalte Genealogien des steirischen Adels um 
1700). The final section of the conference went beyond the borders of historical Styria: Ulrich Becker attributed the depictions of the Liberation of Vienna in 1683 to Stephan Kessler (Weltgeschichte als Wimmelbild. Stephan Kessler und der Entsatz von Wien 1683); Andreas Gamerith dealt with ceiling paintings in the Zwettl and Altenburg monasteries before Troger (Vor Troger. Aspekte der Wandmalerei um 1700 am Beispiel der Klöster Zwettl und Altenburg), and Martin Mádl gave a detailed paper on Czech ceiling painting around 1700 („So ist nun ... der Pracht im Bauen so hoch gestiegen .... Profane Ceiling Painting in Bohemia around 1700).

The conference participants prepared their papers for publication, or contributed new research findings, which are now being published in the Acta historiae artis Slovenica under the title Franz Carl Remp and Painting in the Habsburg Hereditary Lands around 1700. The contributions by Karin Požin and Georg Lechner deepen our knowledge of Remp's ceiling paintings in the Palais Attems, as well of the works he created after moving to Vienna. Some of Remp's oil paintings are also treated in the papers by Edgar Lein, who focuses on the cost of paintings in Styria, and by Renata Komić Marn, who discusses the paintings from the Attems collection in Slovenska Bistrica in Slovenian public collections. The topic of the papers by Polona Vidmar, who focuses on Dominik Franz Kalin von Marienberg's works for the Habsburg family, and Ulrich Becker, who attributes the depictions of the Liberation of Vienna to Tyrolian painter Stephan Kessler, is the painting of the last decades of the $17^{\text {th }}$ century. Andreas Gamerith discusses the Galleria maior in the Zwettl monastery as an experiment in ceiling painting in late $17^{\text {th }}$ century Lower Austria. The volume is concluded by Martin Mádl's contribution, which focuses on the transformation of Central European painting around 1700 and the models that were important for this transformation.

We hope that the diverse contributions and the numerous depictions will encourage further research in Baroque painting. 


\section{VORWORT}

\section{Franz CARl Remp UNd die MAlerei IN DEN HABSBURGISCHEN ERBLANDEN \\ UM 1700}

Trotz einer relativ großen Anzahl von Gemälden ist das CEuvre des in Radovljica in Slowenien geborenen und in Graz sowie Wien tätigen Malers Franz Carl Remp (1675-1718) einer breiten Öffentlichkeit bislang weitgehend unbekannt geblieben. Die erste und bislang einzige Ausstellung mit Werken des Malers wurde vom 26. Oktober 1973 bis zum 19. Mai 1974 im Unteren Belvedere in Wien und im Juni 1974 im Ecksaal der Alten Galerie des Joanneums in der Grazer Neutorgasse gezeigt. Das Katalogbändchen mit dem Titel Der Barockmaler Franz Carl Remp 1674-1718 enthält eine sieben Seiten umfassende Einführung zu Leben und Werk des Künstlers, einen Katalogteil mit zwanzig Einträgen, eine Zeittafel und ein Literaturverzeichnis.

Georg Lechner hat sich im Rahmen seiner 2010 in Wien abgeschlossenen Dissertation umfassend mit Franz Carl Remp befasst. Als Lechner im Frühjahr 2018 darauf hinwies, dass sich der 300. Todestag des Malers im Herbst nähere, aber weder in Wien noch in Graz eine Ausstellung mit Werken des Barockmalers geplant sei, beschlossen die Herausgeber, eine Tagung zu organisieren, die am 23. November 2018 unter dem Titel Maler und Auftraggeber. Franz Carl Remp und die Malerei in der Steiermark um 1700 im Laterneng'wölb von Schloss Eggenberg abgehalten wurde. Ergänzend dazu gab es am darauffolgenden Tag eine Besichtigung des Palais Attems unter der Leitung von Georg Lechner sowie eine Führung von Paul Schuster durch die Prunkräume von Schloss Eggenberg. Die von den Universitäten in Graz und Maribor sowie dem France Stele Institut für Kunstgeschichte am Forschungszentrum der Slowenischen Akademie der Wissenschaften und Künste unterstützte Veranstaltung war Teil des von der Slowenischen Forschungsagentur und dem Österreichischen Austauschdienst finanzierten bilateralen Projekts BI SLO-AT/16-17-18: Art Patrons as Carriers of Province's Identity. The Role and Significance of Commissioners of Architectures and Furnishings of Aristocratic Residences and Pilgrimage Sites in Styria sowie des von der Slowenischen Forschungsagentur finanzierten Forschungsprojekts J6-7410: Visual Representations of the Nobility. Early Modern Art Patronage in the Styria Province (2016-2018).

Den Anfang der Tagung machten Georg Lechner mit einem grundlegenden Vortrag über Franz Carl Remp zwischen Graz und Wien und Christine Rabensteiner mit Werke immigrierter und gebürtiger steirischer Barockmaler. Ein Blick in das Depot der Alten Galerie sowie Karin Požin mit einer Case Study of Remp's Ceiling Paintings in Palais Attems in Graz. From Reproductive Prints to Frescoes. Im zweiten Teil untersuchten Edgar Lein Preis und Wert der Malerei um 1700 und Tina Košak The Forchondt Art Dealers and their Styrian Clients. Excerpts from the Antwerp City Archives. Renata Komić Marn analysierte The Portraits of Eleonora Maria Rosalia Princess of Eggenberg und Polona Vidmar präsentierte Gemalte Genealogien des steirischen Adels um 1700. Den Blick über die Steiermark hinaus weiteten Ulrich Becker mit seinem Vortrag Weltgeschichte als Wimmelbild. Stephan Kessler und der Entsatz von Wien 1683, Andreas Gamerith mit einem Blick auf die Malerei Vor Troger. Aspekte der Wandmalerei um 1700 am Beispiel der Klöster Zwettl und Altenburg und Martin Mádl mit einem umfassenden Vortrag zum Thema „So ist nun ... der Pracht im Bauen so hoch gestiegen ..... Profane Ceiling Painting in Bohemia around 1700. 
Die Referenten und Referentinnen überarbeiteten ihre Vorträge für die Drucklegung oder präsentierten neue Forschungsergebnisse, die wir in den Acta historiae artis Slovenica unter dem Titel Franz Carl Remp und die Malerei in den habsburgischen Erblanden um 1700 veröffentlichen. Die Beiträge von Karin Požin und Georg Lechner erweitern das Wissen über Remps Wandmalereien im Palais Attems und über sein nach der Übersiedlung nach Wien geschaffenes Werk. Einige Ölgemälde Remps werden auch in den Beiträgen von Edgar Lein, der sich den Kosten für Gemälde in der Steiermark widmet, und Renata Komić Marn, die die Gemälde der ursprünglich in Schloss Slovenska Bistrica befindlichen Sammlung Attems in slowenischen öffentlichen Sammlungen untersucht, behandelt. Die Malerei in den letzten Jahrzehnten des 17. Jahrhunderts ist das Thema der Beiträge von Polona Vidmar, die die Werke Dominik Franz Calins von Marienberg für das Haus Habsburg präsentiert, und Ulrich Becker, der zwei Darstellungen des Entsatzes von Wien dem Tiroler Maler Stephan Kessler zuschreibt. Andreas Gamerith thematisiert die Galleria maior in Stift Zwettl als ein Experiment der Deckenmalerei des späten 17. Jahrhunderts in Niederösterreich. Der Band endet mit dem Beitrag von Martin Mádl, der sich der Transformation der mitteleuropäischen Wandmalerei um 1700 und ihren bedeutenden Vorbildern widmet.

Wir hoffen, dass die vielfältigen Beiträge und die zahlreichen Abbildungen zu einer weiteren Beschäftigung mit der Barockmalerei anregen werden.

Edgar Lein, Polona Vidmar 


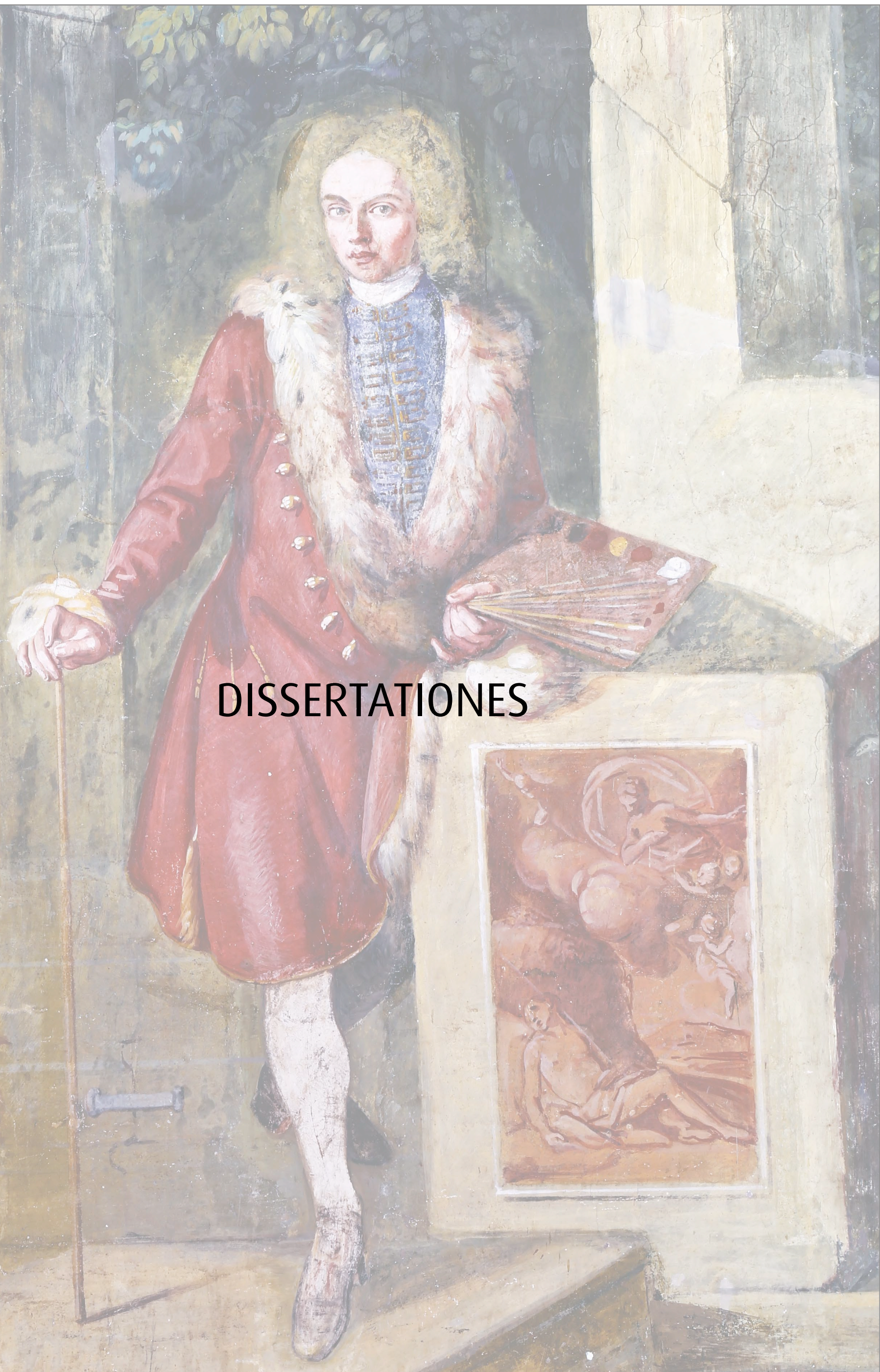




\title{
Zeit des Experiments
}

\section{Die Galleria maior des Stiftes Zwettl als Beispiel für seicenteske Wandmalerei in Niederösterreich}

\author{
Andreas Gamerith \\ Dr. Andreas Gamerith, Zisterzienserstift Zwettl, Stiftsarchiv und Bibliothek, Stift Zwettl 1, A-3910 Zwettl, \\ a_gamerith@yahoo.de
}

\author{
Izvleček: \\ Čas eksperimentiranja. Galleria maior v samostanu Zwettl kot primer stenskega slikarstva \\ 17. stoletja v Spodnji Avstriji
}

1.01 Izvirni znanstveni članek

Značilen primer eksperimentalne faze stenskega slikarstva 17. stoletja je tako imenovana Galleria maior (1679-1681; delno uničena 1778) v cistercijanskem samostanu Zwettl v Spodnji Avstriji. Notranja oprema monumentalne 51 metrov dolge slavnostne dvorane, ki se je nahajala ob opatijskem reprezentativnem dvorišču, je obsegala alegorične skulpture, alegorije kozmičnega reda in svetopisemske junake ter umetno grotto na sredini. Na stropu sta bili s tempero naslikani serija starozaveznih prizorov, delo Sebastiana Fabra iz Nürnberga, in vrsta genealoških portretov, ki so prikazovali vladarje sveta od biblijskih časov do tedanjega habsburškega cesarja. V ikonološkem pogledu lahko opremo dvorane opredelimo kot metaforično dokazovanje pomena pokornosti Božjim zapovedim, kazni kot posledice nepokorščine in zveze med Državo in Cerkvijo.

Ključne besede: samostan Zwettl, samostan Altenburg, baročno slikarstvo, stensko slikarstvo, Sebastian Faber

\begin{abstract}
:
The Time of Experimentation. The Galleria maior in the Zwettl Abbey as an Example of Seicento Wall Painting in Lower Austria

1.01 Original scientific article

The so-called Galleria maior (1679-1681, destroyed by 1778) in the Cistercian abbey of Zwettl in Lower Austria is a typical example of the experimental phase of $17^{\text {th }}$ century wall painting. The inner decoration of this majestic, 51 metres long festival hall, which was located in the abbey's monumental courtyard, comprised allegorical sculptures of the cosmic order and biblical heroes, as well as an artificial grotto in the middle of the hall. The ceiling, painted in tempera, showed a series of nine biblical subjects by Sebastian Faber from Nuremberg, as well as a series of genealogical portraits, representing monarchs from different parts of the world from biblical times to the contemporary Habsburg emperor. The iconological message of the decoration can be summarised as a metaphorical representation of 'obedience to the divine commandments' and 'punishment for disobedience', on the one hand, and a metaphorical representation of the union of the Church and State, on the other.
\end{abstract}


Überblickt man den Bestand der monumentalen Wandmalerei Österreichs, ist die Bedeutung der Klöster und Stifte als Auftraggeber kaum zu übersehen. Die Ausdrucksmöglichkeiten, die die Freskomalerei bot, wurden in den geistlichen Häusern redlich ausgekostet, wobei der dekorative Wert ebenso wie der repräsentative und propagandistische Gehalt erkannt wurde. Nicht nur dem Umstand der zufälligen Erhaltung mag es deshalb geschuldet sein, dass ein Großteil der bedeutenden Freskomalerei des Wiener Umlands in den Barockpalästen der Prälaten, den Klöstern und nicht jenen des Adels überliefert ist. Grans politisierende Kuppel des Kaisersaals in Klosterneuburg, Reiners raffinierte Dekoration in Gaming (wo die Kartäuser nicht vor einer herzlich profan gewürzten Programmatik zurückschreckten) oder das ikonologische Rätselspiel des Altenburger Abtes Placidus Much - die Reihe faszinierender Wandmalereien auf höchstem Niveau lässt sich im Umfeld der kaiserlichen Residenz beinahe beliebig fortsetzen, ohne vorbehaltslos eine Entsprechung auf säkularem Gebiet zu finden.

Zugleich täuscht diese Blüte, die sich im 18. Jahrhundert feststellen lässt, über die Tatsache hinweg, dass den hochkarätigen Projekten des Spätbarock eine interessante Phase des zu Ende gehenden Seicento voranzustellen ist. ${ }^{1}$ Auch wenn weder deren künstlerisches Niveau noch ihre programmatische Dichte den Kapazitäten der nachfolgenden Ausstattungen entsprechen mag: Die frühen „Experimente“ im Medium Wandmalerei bildeten essentielle Auftakte, mit denen die mitteleuropäische Hochzeit der Malerei al fresco eingeleitet werden sollte.

Ein Beispiel für Wandmalerei aus dem Zisterzienserstift Zwettl, die „Galleria maior“ (vollendet 1681), wurde für die Analyse ausgewählt, um die Möglichkeiten des Mediums Fresko in seiner Frühphase zu beleuchten. Wie die knapp ein Jahrzehnt später entstandene Galerie des benachbarten Benediktinerklosters Altenburg, der sogenannte „Türkensaal“ (nach 1689), dokumentiert das Zwettler Projekt die neuen Dimensionen der Repräsentation, die sich aus dem Engagement in Belangen der katholischen Reform ab dem Beginn des 17. Jahrhunderts legitimierten. In der Tradition des mitteleuropäischen, profanen Schlossbaues wurden in beiden Klöstern, die zwar derselben Kulturlandschaft, nicht aber demselben Orden angehörten, die mittelalterlichen, heterogenen Klosteranlagen zu vereinheitlichten Gebäudekomplexen umgewandelt und überformt. Besonders bemerkenswert ist der verbindende Umstand, dass im Zuge dieser früh- resp. hochbarocken Umgestaltungen in beiden Abteien repräsentative Säle im Typus einer „Galerie“ errichtet wurden, ${ }^{2}$ die in ihrer Programmatik bereits dem Typus des „Kaisersaals ${ }^{\text {“3 }}$ zuzurechnen sind und in denen die Wandmalerei neben einer rein dekorativ-repräsentativen Aufgabe vor allem Ansprüche des politischen Selbstverständnisses affirmativ zum Ausdruck brachte.

1 Deckenmalerei um 1700 in Europa. Höfe und Residenzen (Hrsg. Stephan Hoppe, Heiko Laß, Herbert Karner), München 2020.

2 Christina STRUNCK, Die Galerie in der Literatur. Historische Quellen zur Definition, architektonischen Gestalt, idealen Ausstattung und Funktion von Galerien, Europäische Galeriebauten. Galleries in a Comparative European Perspective (1400-1800). Akten des Internationalen Symposiums der Bibliotheca Hertziana, Rom, 23.-26. Februar 2005 (Hrsg. Christina Strunck, Elisabeth Kieven), München 2010, S. 9-32; Nicolas COURTIN, Les grandes galeries européennes. XVIIe-XIXe siècle, Bulletin Monumental, 171/1, 2013, S. 80-81. Für vielfältige Hinweise danke ich Dr. Friedrich Polleroß, Institut für Kunstgeschichte, Wien.

3 Friedrich POLLEROSS, Imperiale Repräsentation in Klosterresidenzen und Kaisersälen, Alte und moderne Kunst, 30/203, 1985, S. 17-27. 


\section{Die malerische Ausstattung der Galleria Maior im Zisterzienerstift Zwettl, um 1681}

\section{Vorgeschichte und Aussehen}

Entgegen der einst so rigiden Bilderpolitik des Zisterzienserordens wurden in Zwettl bereits zu Beginn des 17. Jahrhunderts großzügige Umgestaltungsmaßnahmen getroffen, bei denen auch die Wandmalerei eine wesentliche Rolle spielte. Eine Neugestaltung des gotischen Hallenchors von Zwettl findet sich bei dem 1616 vollendeten Altarbild Die Messe des hl. Martin dokumentiert, bei dem der Passauer Maler Georg Kurz ein Wunder des Heiligen in der Stiftskirche von Zwettl lokalisiert. ${ }^{4}$ Sieht man in den vorderen beiden Seitenkapellen links vorne noch den leeren Altarschrein und zerstörte Mönchsfiguren - die Renovierung der Ausstattung ist hier also erst im Gange -, präsentieren sich die anderen Kapellen bereits als vollständig erneuert. Die Interventionen beschränkten sich dabei nicht bloß auf neu angeschaffte Altarretabel, auch die Raumschale der Kapellen war - ganzheitlich - in das Konzept miteinbezogen (ein Befund, der sich auch im Zuge der Kirchenrestaurierung 2011 bestätigte). ${ }^{5}$ Innerhalb der einzelnen Seitenkapellen präsentierte sich ein ornamentales Geflecht, in das Bildmedaillons mit Heiligen eingefügt wurden. Kapellenübergreifend ergaben sich aber gleichzeitig regelrechte „Interaktionen“ auf Basis von Malerei: Die Altäre wurden von gemalten Engeln mit Baldachinen bekrönt, die mit weiteren Engeln (als Wappenträgern) an den Schildbögen zum Hauptraum korrespondierten. Die inhaltliche Dimension dieser malerischen Gestaltung beschränkte sich mehr oder weniger auf den dekorativen Gehalt, die Kapellen ergaben als analoge Raumzellen ein geschlossenes und konzises Erscheinungsbild. Die Protagonisten der Malerei waren freilich austauschbar und verfügten über kein spezifisches Aussagepotential. Selbst die auffälligen Grotesken, die an der Brüstung des Querhauses angebracht waren, waren rein als Drolerien ohne ikonologische Bedeutung zu verstehen. Mochte es hier auch wimmeln von Eichkätzchen, Schnecken, einer Elster, einem Pfau, einem Storch mit Kröte oder einem naschenden Häschen: Die an Teppiche gemahnenden, gemalten Brüstungsbehänge hatten rein dekorative Zwecke zu erfüllen und konnten den Betrachter (noch) nicht zu tiefsinnigen konzeptuellen Schlüssen reizen. Charakterisierend lässt sich festhalten: Obwohl die Wandmalerei zu Beginn des 17. Jahrhunderts bereits in ihrer Möglichkeit wahrgenommen wurde, einzelne Gestaltungseinheiten (hier die einzelnen Kapellen) miteinander ästhetisch zu verbinden, blieben diese inhaltlich voneinander unabhängig. Den Entwicklungsschritt einer inhaltlich zusammenhängenden Bildausstattung ${ }^{6}$ gewährleistete in Zwettl erst das sechzig Jahre später realisierte Großprojekt der Galleria maior.

Bereits kurz nach seinem Regierungsantritt hatte Abt Kaspar Bernhard (reg. 1672-1695) mit einer grundlegenden Neuorganisation des Klostergebäudes begonnen. ${ }^{7}$ Zum ersten Mal waren die verschiedenen Lebensbereiche des Klosters (Klausur, Landwirtschaft, etc.) auch in ihrer Verortung im Gebäude eindeutig voneinander getrennt worden und hatten erstmalig eine klare räumliche $\mathrm{Ab}$ grenzung erfahren. Dass der repräsentative, d.h. unklösterliche Bereich im Zuge dessen expandierte,

4 Christina KAPEUNDL, Georg Kurz und die frühbarocken Gemälde für die Stiftskirche Zwettl, Wien 2012 (unpublizierte Diplomarbeit).

5 Petra WEISS, „Denkmäler sind häufig Flickenteppiche...“. Geschichte der Kirchenrestaurierung, Zisterzienserstift Zwettl. Die Restaurierungsgeschichte (Hrsg. Franz Romeder), St. Pölten-Salzburg-Wien 2013, S. 85.

6 Vgl. Karl MÖSENEDER, Deckenmalerei, Barock (Hrsg. Hellmut Lorenz), München-London-New York 1999 (Geschichte der bildenden Kunst in Österreich, 4), S. 303-306.

7 Ralph ANDRASCHEK-HOLZER, Altenburg und Zwettl. Ansichten zweier Klöster, Das Waldviertel, 64/3, 2015, S. 205-225; Karl KUBES, Frühbarocke Architektur und Kunst, Stift Zwettl und seine Kunstschätze (Hrsg. Karl Kubes, Joachim Rössl), St. Pölten-Wien 1979, S. 76-82. 
zeigt sich an der Errichtung eines zusammenhängenden Gästetraktes ebenso wie an der Etablierung eines Prälatengartens, ${ }^{8}$ der dem Abt und seinen Gästen vorbehalten sein sollte. ${ }^{9}$

Neben dieser äußeren Umgestaltung ließ Abt Kaspar aber auch bei der Innengestaltung seines Hauses neue Maßstäbe setzen. Selbst wenn diese Interventionen später durch die Neugestaltungen des 18. Jahrhunderts erneut verschwunden sind, wird aus den erhaltenen Rechnungsbelegen eine beeindruckend umfangreiche Kampagne ersichtlich, die eine völlige Barockisierung des Klosterkomplexes am Ende des 17. Jahrhunderts vor Augen führt.

Im Jahr 1676 hatte man den Crustarius /seu ut vulgo dicitur: Stuccadorer/ Domenico Piazoll aus Wien nach Zwettl berufen und ihn mit der Erneuerung des Refektoriums, den Chorbögen der Stiftskirche, der neuen Bibliothek sowie der neuen Tafelstube beauftragt. ${ }^{10}$ Die wesentlichen repräsentativen Bauaufgaben sollten somit im modernen Sinne neu gestaltet werden. Drei Jahre später erfolgte am 2. April zusätzlich die Vertragsunterzeichnung zum Großen Saal sambt denen zway Seithen Zümmern, wofür die stolze Summe von 600 Gulden festgelegt wurde. Während die anderen Arbeiten Piazolls durch spätere Überarbeitungen vernichtet wurden, konnten 1893 bedeutende Reste dieses Saals in einem Zwischenboden des Westtraktes des Abteihofs entdeckt werden (Abb. 1). ${ }^{11}$ Selbst der Torso dieser Ausstattung, deren fehlende Teile durch die erhaltenen Künstlerabrechnungen rekonstruierbar werden, zeichnet ein beeindruckendes Bild des einstigen Ensembles: Die Zwettler Galleria maior erstreckte sich als 51 Meter langer, tonnengewölbter Saal über den gesamten Eingangstrakt des Klosters. Die Belichtung erfolgte, dem Galerie-Typus entsprechend, über die gesamte Länge nach zwei Seiten hin (Osten und Westen), was eine stark wechselnde, jedoch dauerhaft günstige Lichtsituation während des Tages bedeutete. Die Wölbung des Saales war durch Stichkappen über den je neun Fensterachsen akzentuiert, die Gliederung des mächtigen Gewölbes erfolgte durch stuckierte Rahmenstrukturen. Diese entsprachen in ihrer kräftigen Formulierung mit krautigem Akanthus und starkem Rollwerk ganz den Ideen der zeitgenössischen Wiener Stuckatur ${ }^{12}$ und boten Raum für eingefügte Malereifelder (Abb. 2). Im unteren Bereich des Saales waren in Nischen sechzehn knapp unterlebensgroße Figuren aufgestellt (per 150 Gulden), die Abt Kaspar bereits im

8 Doris GRETZEL, Bertram CHIBA, Hinter Mauern und Zäunen. Die Gärten des Stiftes Zwettl, Zwettl 2006 (Zwettler Zeitzeichen, 11), S. 37-39.

9 Auch die Abtei als Wohnung des Abtes wurde verlegt. War sie zuvor als separates Gebäude am Kamp situiert gewesen, verlagerte sie Abt Kaspar in den Bereich zwischen Gästetrakt und Klausur, sodass sie auch baulich die Zwischenposition des Prälaten als Vertreter des Hauses nach außen sowie als Vorsteher der Mönchsgemeinschaft verdeutlichte. Ob die Verlagerung auch als moralische Aufwertung und stärkere Anbindung des Abtes ins Klosterleben zu verstehen ist, ist nicht klar - wenn der Abt die vorherige Abtei als quae magis dehonestamento erat abbatibus huius loci, quam ornamento aut honestati („die den Äbten dieses Hauses mehr zum Schimpf als zur Zierde und Ehre gereichte") bezeichnet, bleibt unklar, ob mit der räumlichen Separierung auch ein Abweichen vom klösterlichen Lebenswandel unterstellt wurde. Zitiert nach Paul BUBERL, Die Kunstdenkmäler des Zisterzienserklosters Zwettl, Wien 1940 (Ostmärkische Kunsttopographie, 29), S. 287, Nr. 238.

10 Stiftsarchiv Zwettl, StiAZ 2/17, olim Handschrift 294a.

11 Hermann von RIEWEL, Neue Funde im Stifte Zwettl 1893, Mittheilungen der k. $k$. Central-Commission zur Erforschung und Erhaltung der Kunst- und historischen Denkmale, n. F. 21, 1895, S. 87-90. 1897 wurden Elemente der wiedergefundenen Stuckdekoration bei der Neugestaltung des Zwettler Winterrefektoriums malerisch aufgegriffen.

12 Ingeborg SCHEMPER, Stuckdekorationen des 17. Jahrhunderts im Wiener Raum, Wien-Köln 1983 (Dissertationen zur Kunstgeschichte, 17); Jakob WERNER, Barocker Stuckdekor und seine Meister in Stift Altenburg, Benediktinerstift Altenburg 1144-1994. 850 Jahre Benediktinerstift Altenburg (Hrsg. Ralph Andraschek-Holzer), St. Ottilien 1994 (Studien und Mitteilungen zur Geschichte des Benediktinerordens und seiner Zweige, Ergänzungsband 35), S. 300-301. 


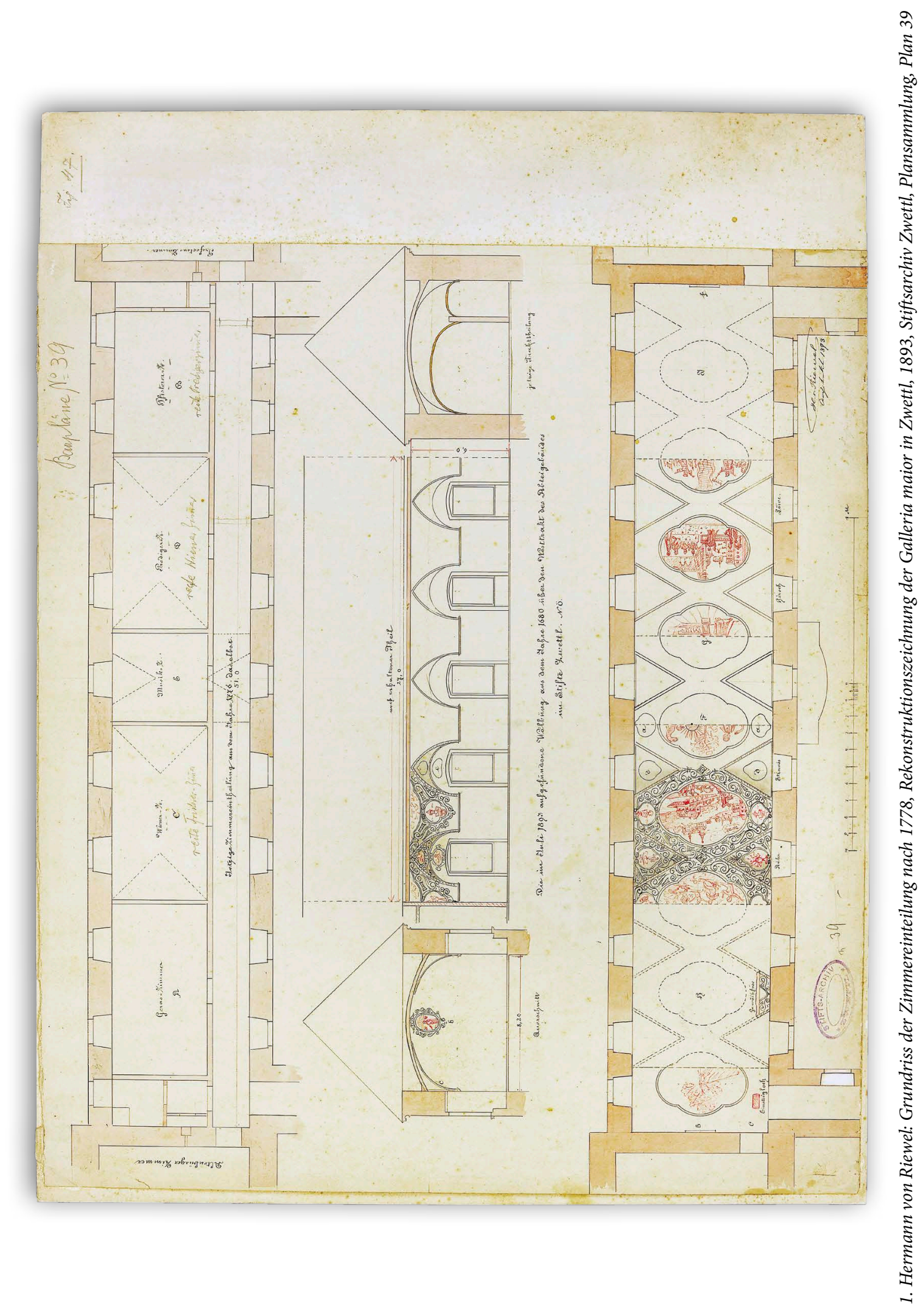




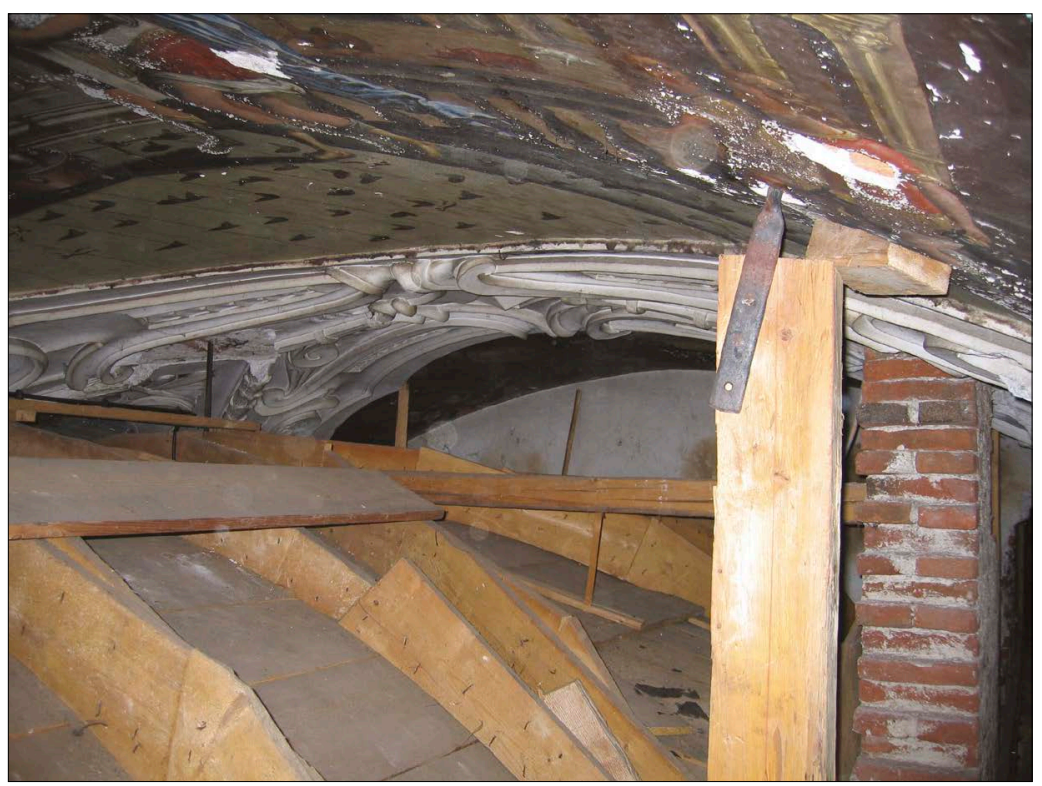

2. Domenico Piazoll und Sebastian Faber: Stuck und Malereien des 7. Gewölbejochs, Einblick mit Zwischendecke (1778), Galleria maior, Stift Zwettl

Oktober 1678 - also noch vor der Stuckatur - in Auftrag gegeben hatte, als nemblichen Moyses, Aaron, Noe und Davidt, Item die vier Thail der Weldt, vier Jahreszeiten und dann die vier Sybilien, mit allen ihren zugehörungen und Symbolis iedes $41 / 2$ Schuch hoch, und 1 11/2 Schuch braidt sambt den posumenteln von guetten und feinem Stain, Sauber und Gerecht machen, daß Ihr Hochw- und Gnaden damit ihr contento haben. ${ }^{13}$ Keine Vorstellung erhalten wir über das Aussehen der beiden angrenzenden Räume, die Abt Kaspar aus zwei ehemaligen Wehrtürmen umgestalten ließ; hier fiel die komplette Ausstattung späteren Umbauten zum Opfer. Auch das an den Saal in der Mitte anschließende Turmzimmer, das im Unterteil des 1777 abgetragenen Kanzleiturms untergebracht war, entzieht sich genauerer Kenntnis. Dies ist besonders bedauerlich, da hier eine künstliche Grotte errichtet worden war: nit weniger auch den Thurn ober deß Thor in vormb ainer Crota mit der darzue behörigen arbeith. ${ }^{14}$ Pro grotta erwarb Abt Kaspar auch beim Regensburger Kaufmann Löschenkol am 4. August 1679 Muscheln im Wert von 35 Gulden; ${ }^{15}$ das Aussehen der Grotte wird damit im Wesentlichen wohl anderen Ausstattungen aus der Mitte des 17. Jahrhunderts vergleichbar gewesen sein (etwa in Červený Kameň (Bibersburg)), wo Stuckelemente mit künstlichen Felsformationen in Verbindung standen. Die Zwettler Grotte, ungewöhnlicherweise im ersten Stock (anstelle zu ebener Erde) situiert, ist als Hinweis darauf zu deuten, dass der Saal eine eigenartige Zwischenposition zwischen Festsaal und Sala terrena einnehmen sollte - ein Terminus, den der Bauherr selbst übrigens in seinem Diarium bei Fertigstellung des Saales verwendete. ${ }^{16}$ Es bleibt zu vermuten, dass diese Zwitterstellung durch die topographische Lage des Zisterzienserstiftes hervorgerufen wurde, bei der der zweigeschossige Gästetrakt verhältnismäßig tief zu liegen kommt und durch einen Terrainsprung den Eindruck eines ebenerdigen Gebildes erweckt. Im Inneren sollte der Saal hauptsächlich vom Grottenraum aus erschlossen werden, wie die Anordnung der erhaltenen Deckenbilder nahe legt,

\footnotetext{
13 Stiftsarchiv Zwettl, StiAZ Lade 199 - III - 1a.

14 Stiftsarchiv Zwettl, StiAZ Lade 19 - I - 3, Vertrag mit Piazoll, 2. April 1679.

15 BUBERL 1940 (Anm. 9), S. 288, Nr. 244.

16 BUBERL 1940 (Anm. 9), S. 289, Nr. 256.
} 
die sich - ihrer chronologischen Erzählfolge zum Trotz - in zwei inhaltlichen Strängen von der Saalmitte aus entwickeln. ${ }^{17}$

\section{Die Deckenbilder}

Im Juni 1678, noch vor der Beauftragung Piazolls, wurde ein aus Nürnberg stammender novus pictor namens Sebastian Faber in Zwettl vorstellig, quem ad faciendas picturas suscepi („den ich für die zu schaffenden Bilder aufnahm"), wie der Abt in seinem Diarium vermerkte. Als Wochenlohn wurde ein Gulden ausgehandelt. ${ }^{18}$ Bis zum 5. Oktober 1681 schweigen die Quellen über die Tätigkeit Fabers in Zwettl, erst dann erscheint erneut ein Maler für den Saal, allerdings namentlich ungenannt (!), in den Aufzeichnungen Abt Kaspars: Sala terrena seu galleria a pictore integraliter absoluta fuit, sicut et quartus tractus monasterii. („Die Sala terrena oder Galleria ist vom Maler völlig fertiggestellt wie auch dieser gesamte Trakt des Klosters"). ${ }^{19}$ Wie der Prälat die Bekanntschaft Fabers gemacht hatte und welche Referenzen diesen für die Aufgabe qualifizierten, ist nicht bekannt. Die Beauftragung eines auswärtigen Künstlers zeigt jedenfalls den noch herrschenden Mangel an (einheimischen) erfahrenen Großmalern in den letzten Dekaden des Seicento.

Dabei manifestieren sich die Schwächen des Künstlers durchaus in einem etwas spröden Figurenideal und einer trockenen Erzählweise, die an eine Übertragung von Bildfindungen aus dem Kleinformat ins Monumentale denken lässt. Als wären sie den Seiten einer illustrierten Bibel entsprungen, entwickeln die Bilder eine detailreiche Sprache, die sich völlig der Überwältigung durch einen raffinierten Illusionismus entzieht. Damit schließt die Galleria maior an gängige Prinzipien des „Stuckbarock“ an, bei dem die Deckenbilder ohne Rücksicht auf ihre Anbringung keinen illusionistischen Höhenzug entwickeln.

Auch technisch bilden die Zwettler Gemälde einen interessanten Zwischenschritt auf dem Weg vom eingesetzten Ölbild (wie im zeitgleich entstandenen Planetensaal von Hans Adam Weissenkircher in Schloss Eggenberg) zur direkt an der Wand entstandenen Malerei. Die großformatigen Mittelstücke, die einen Durchmesser von annähernd fünf Metern haben, sind als Seccomalereien in einer Tempera-/Öltechnik ausgeführt, greifen somit die technischen Möglichkeiten der Tafelmalerei auf, übertragen sie jedoch direkt auf die Wand als Bildträger. Die flankierenden kleinen Emblemata und Blumenstücke wurden hingegen (sekundär?) al fresco umgesetzt (Abb. 3-4), ein Wechsel des malerischen Mediums, der sich völlig einer Erklärung entzieht und für den es keine Parallele geben dürfte. Es stellt sich die Frage, ob hier zwei Maler, vielleicht sogar in unterschiedlichen Zeiten, am Werk waren. Theoretisch könnte Faber nach seiner Beauftragung 1678 lediglich die zentralen Medaillons in Tempera umgesetzt haben, während die Trabantenbilder al fresco entweder bis Oktober 1681 oder überhaupt erst im Zuge einer ersten Restaurierung 1706/1707 (?) von einem anderen Künstler hinzugefügt wurden.

Einigermaßen klar lässt sich trotz der starken Beeinträchtigungen und Fragmentierungen der Bilder im Zuge des Umbaus von 1777/1778 die originale Programmatik des Saales rekonstruieren.

17 Eine Zugangsmöglichkeit von der Durchfahrt im Kanzleiturm her ist nicht anzunehmen; hier unterschied sich die Zwettler Anlage offenbar wesentlich von Parallelprojekten wie Altenburg oder Petronell. Hanna EGGER, Der Triumph der Gerechtigkeit, der Tapferkeit und der Liebe. Zur Ausstattung der Trakte des 17. Jahrhunderts um den Prälaturhof des Stiftes Altenburg, Alte und moderne Kunst, 28/189, 1983, S. 1-7.

18 BUBERL 1940 (Anm. 9), S. 287, Nr. 31.

19 BUBERL 1940 (Anm. 9), S. 289, Nr. 256. 


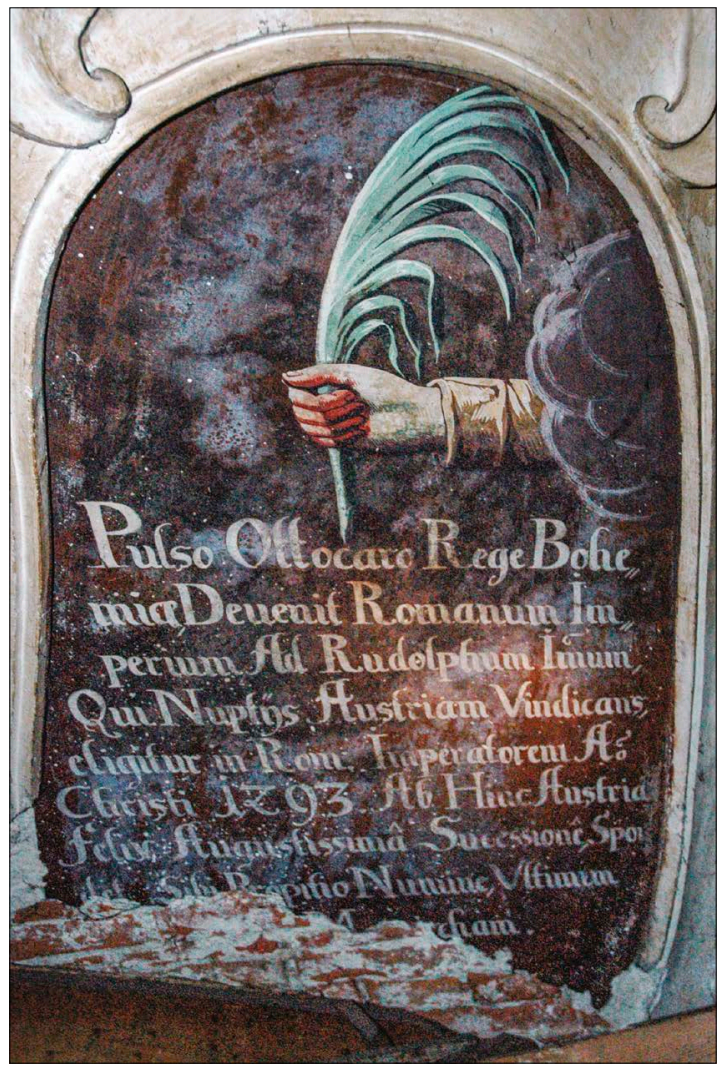

3. Sebastian Faber (?): Emblemkartusche Rudolfs I. von Habsburg, 1679/1681, Galleria maior, Stift Zwettl

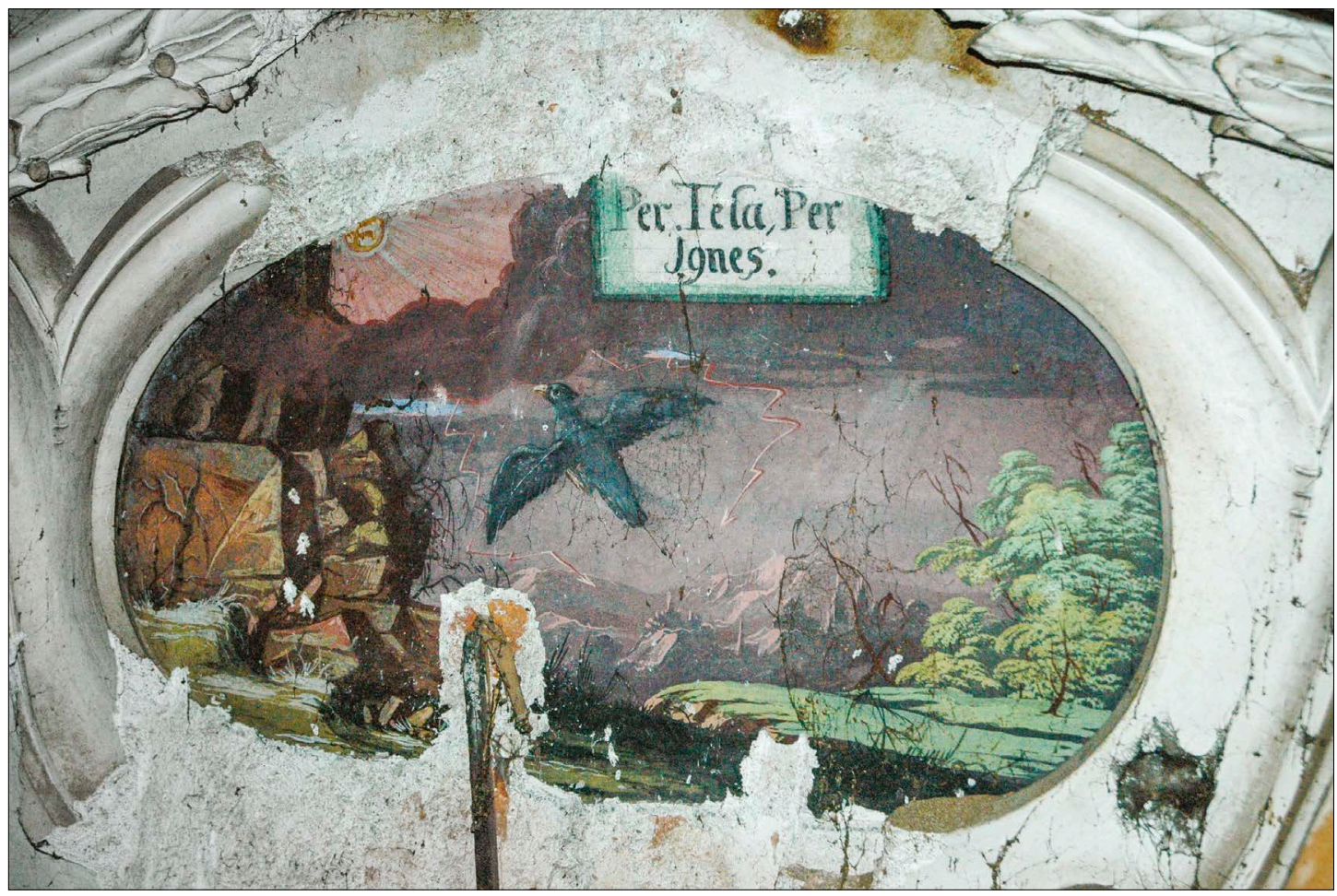

4. Sebastian Faber (?): Emblemkartusche Per tela, per ignes

(Ein Adler steigt einem Gewitter zum Trotz zur Sonne empor), 1679/1681, Galleria maior, Stift Zwettl 


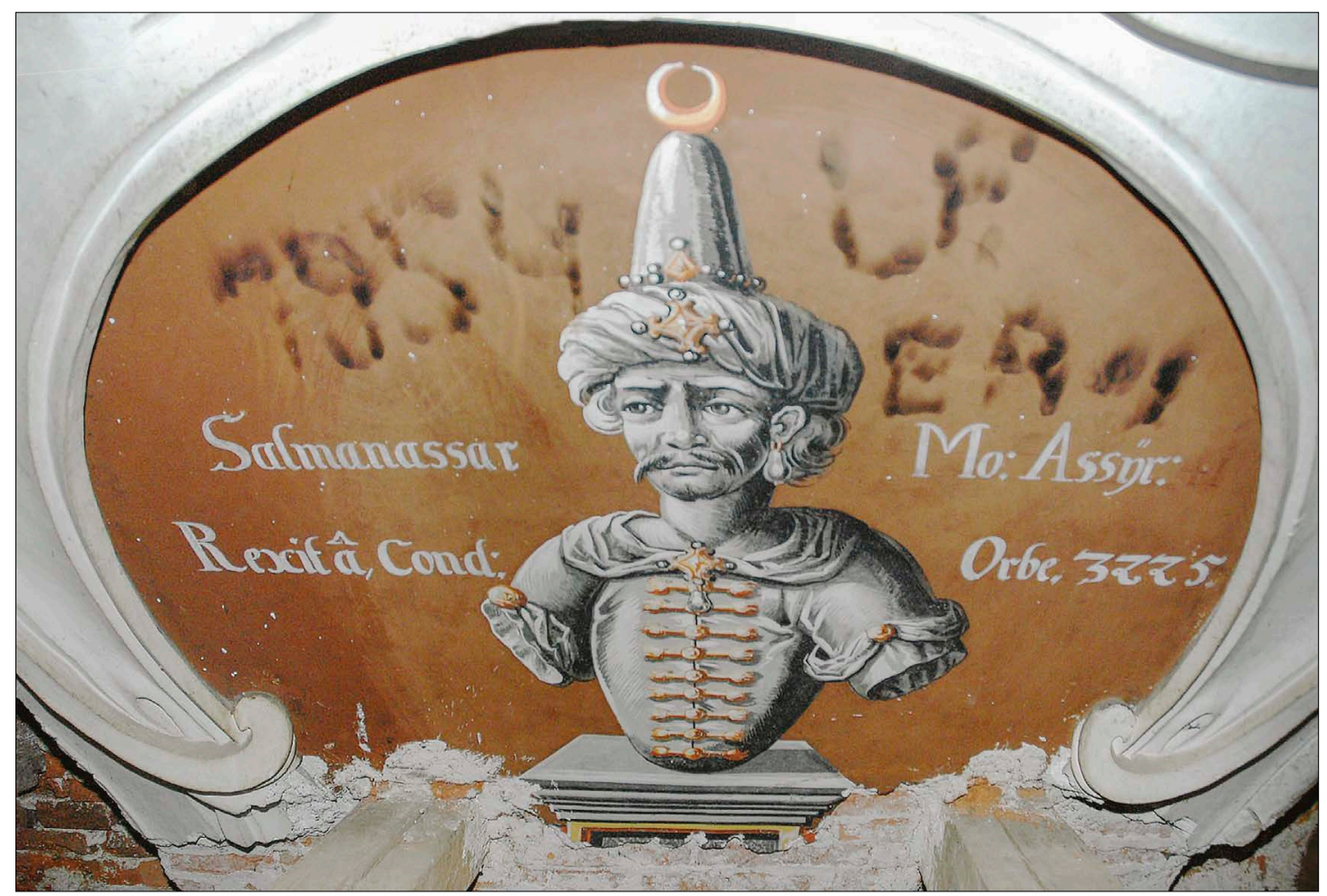

5. Sebastian Faber: Salmanassar, 1679/1681, Galleria maior, Stift Zwettl

Hauptträger der Bildaussagen waren ursprünglich neun Szenen des Alten Testaments, die in die großen Felder in der Mitte des Gewölbes eingefügt wurden. Von diesen sind zwei vollständig, vier zur Hälfte und eines in stark reduziertem Zustand erhalten; zwei Felder wurden vollständig zerstört. In den kleineren Feldern dazwischen fanden sich als Topoi klassischer Herrscherikonographien die Allegorien der vier Weltteile sowie eine Monarchenreihe, die von den ältesten Zeiten der Welt (von Salmanassar über Augustus und Karl den Großen) bis in die Gegenwart reichte (Abb. 5). Das Reiterbildnis des regierenden Kaisers Leopold I. schloss als Medaillon an der südlichen Schmalseite die Herrscherserie ab. Weniger stringent hinsichtlich des Konzepts sind die über den Fenstern befindlichen Emblemata zu verstehen, gleichfalls lose fügten sich farblich zurückhaltende Blumenstücke mit Sinnsprüchen Salomos in das Programm ein - auch sie Zutaten einer späteren Überarbeitung?

Auffälliges Merkmal der Dekoration ist ihr irritierender Aufbau, sozusagen die Wegeführung im Raum: Die Bilder waren zwar alle in dieselbe Richtung orientiert (was eine Lesart von Süden nach Norden implizieren würde); tatsächlich gliederten sich die Deckenstücke aber in zwei Erzählstränge, die von der Mitte des Saales, von der Grotte her, ihren Anfang nahmen. Das bedeutet, dass der Betrachter das Lesen der Bilder von der Mitte des Saales aus beginnen musste, die Leserichtung aber zugleich ein Abschreiten der Bilder vom Südende des Saals bis zur gegenüberliegenden Seite verlangt hätte. (Auch dieser Widerspruch in der Inszenierung, der Lese- und Gehrichtung nicht in Übereinstimmung brachte, offenbart den experimentellen Charakter des Gesamtprojektes.)

Als erstes Bild ist in der Saalmitte die Szene auszumachen, bei der Adam inmitten von exotischen Geschöpfen (unter denen ein Strauß besonders auffällt) von Gott den Auftrag erhält, die Tiere zu benennen (Gen 2,19). Daran schloss das Gebet des Noah an, in dessen Hintergrund die Beladung der Arche mit allen Arten von Tieren sichtbar wird, worunter sich auch zwei Einhörner 


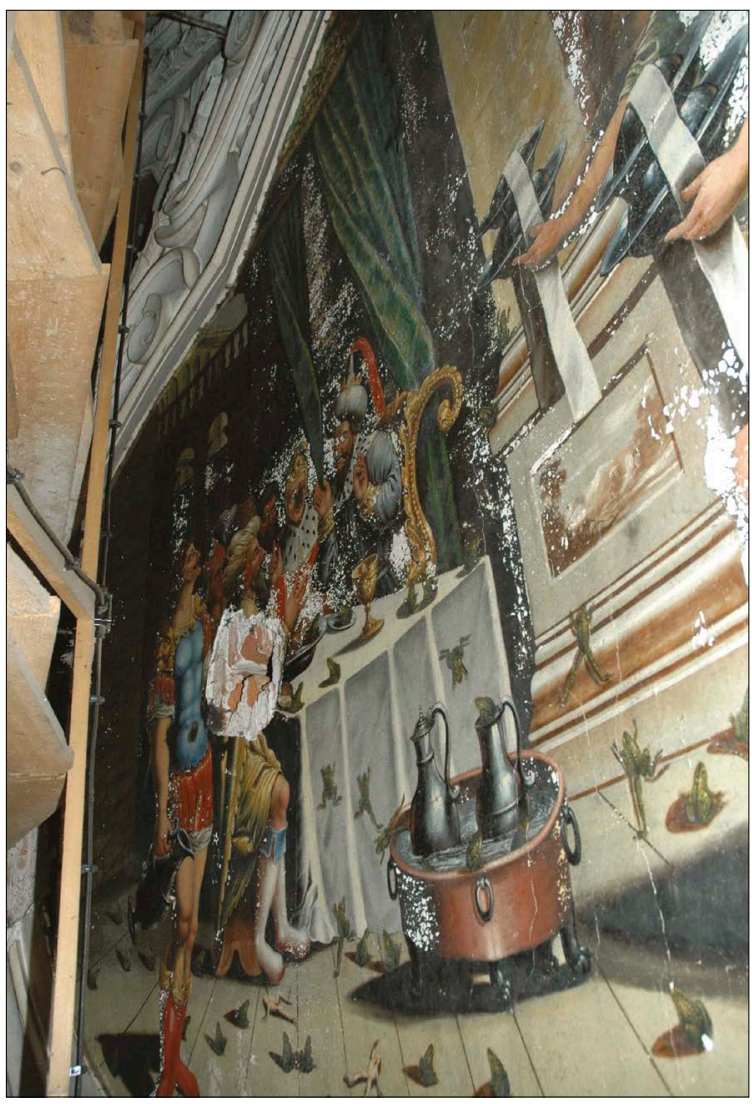

6. Sebastian Faber: Die Plage der Frösche, 1679/1681, Galleria maior, Stift Zwettl

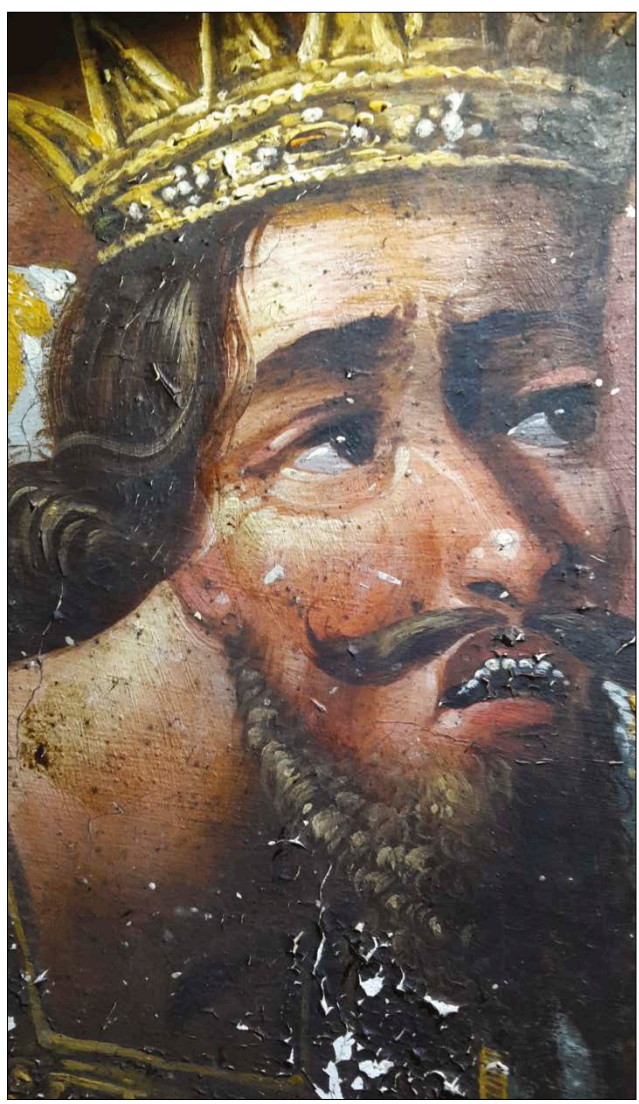

7. Sebastian Faber: Kopf Pharaos, Der Untergang von Pharaos Heer im Roten Meer, 1679/1681, Detail, Galleria maior, Stift Zwettl

befinden (Gen 6,13-16). Bei der anschließenden Sintflut (Gen 7,17-23) ist drastisch die Auslöschung des sündigen Menschengeschlechts geschildert, das für seinen gottlosen Lebenswandel bestraft wird. Nach einem verloren gegangenen Darstellungsfeld (Dankopfer Noahs?) schloss die Szene von Abraham mit den drei Engeln (Gen 18,1-32) den Genesis-Zyklus ab. ${ }^{20}$

Erneut von der Mitte aus, nun aber korrekt zu lesen, folgte ein Zyklus der Exodus-Geschichte. Im ersten Feld war wohl Moses zu sehen, der dem Pharao die Plagen Ägyptens androhte (Ex 5, 1-5) - hier ist lediglich die Palastarchitektur in der Bodenzone erhalten geblieben. Vollständig überliefert ist hingegen die Folgeszene, bei der mit unzähligen Fröschen und verendeten Tieren im Hintergrund die Erfüllung von Moses Drohungen geschildert wird (Ex 8,1-11; 11,5; Abb. 6). Der Untergang Pharaos im Roten Meer beschließt heute den Zyklus (Ex 14,27-30; Abb. 7), dem im originalen Zustand wohl noch eine Darstellung des Dankgebets des Moses folgen sollte, ${ }^{21}$ von dem sich, ebensowenig wie von dem Gegenstück zu Kaiser Leopolds Reiterbildnis (Rudolf I. von Habsburg?) keine Spuren erhalten haben.

${ }^{20}$ Hier ist das Bildfeld derart stark reduziert, dass nur die Hütte und ein als eine der Eichen von Mamre zu deutender Baum zu erkennen sind.

21 Ebenfalls denkbar wäre eine Szene der David-Geschichte (Salbung Davids zum König?), die den Bezug zur Skulptur Sturmbergers hergestellt hätte. 
Bringt man den ursprünglich im Saal aufgestellten (verlorenen) Skulpturenzyklus mit den erhaltenen Deckenbildern in Übereinstimmung, so ergibt sich ein verblüffendes Bild: In den Statuen wie der prinzipiellen architektonischen Disposition des Saales (v.a. mit der Grotte als Entree) war die profane Inhaltsebene - vertreten durch die Statuen der vier Jahreszeiten und der vier Erdteile - stark hervorgehoben. Die Verbindung zu einer sakralen Sinnebene erschien hier beinahe lose. Erst die Kombination der Skulpturen der Patriarchen Moses, Aaron, Noah und David mit den Deckenbildern führte zu einer stringenteren Deutung des Ensembles, zu einer Interpretation, die sich nicht nur in den Dienst der kaiserlichen Sache stellte, sondern auch (durch die eminente Bedeutung des Priesters Aaron) die Rolle des Priestertums für das politische Heil vor Augen führte. Denn die Kaiserserie und das prominente Auftreten des Moses dürfen nicht darüber hinwegtäuschen, dass die weltliche "potestas“ in diesen Bildern durch die Mithilfe des Priesters vehement legitimiert wurde: Das Handeln des Führers des Gottesvolkes erhält erst durch die Unterstützung durch das Priestertum seine Berechtigung. „Ordnung“ als natürliches Prinzip wird hier fast unmerklich instrumentalisiert: Wie die kosmische Ordnung der Jahreszeiten gewährleistet auch der Bund von Politik und Religion die Ordnung der Welt. In der Huldigung des Herrschers wird damit die Notwendigkeit eines Gehorsams gegenüber dem Willen Gottes eingefordert. Wenn die Bilder der Sintflut, der Froschplage und (wahrscheinlich) des Gesprächs mit Abraham über die Zerstörung Sodoms gewählt wurden, dann vorrangig, um die Konsequenzen des „Ungehorsams wider das Göttliche“ vor Augen zu führen. Die Sibyllen, trotz ihres Heidentums erleuchtete Künderinnen des Heils, bildeten dabei die inhaltliche Ergänzung, indem sie das Geschehen des Alten Bundes in das Licht einer gesamthistorischen Entwicklung und Prädestination zu rücken hatten.

Ergebnis der Gesamtausstattung war somit eine absolut konsequente inhaltliche Abstimmung zwischen der Malerei und der skulpturalen Bespielung des Saales. Die Bedeutung der (Monumental-)Malerei erwies sich dabei als erheblich gestärkt, verfügte sie doch nicht mehr bloß über jene ornamentale Beliebigkeit, die ihr noch 1616 bei der Erneuerung der Zwettler Stiftskirche beigemessen worden war. Auch wenn der dekorative Wert der Bilder nach wie vor eine große Rolle spielte: Die narrative Dichte in den Bildern hatte sich wesentlich gesteigert, das Einzelbild war in seiner Didaktik einem universelleren Konzept unterworfen, was Folgen für das Verständnis der gesamten Architektur zeitigen sollte. Nicht die Kostbarkeit der verwahrten Objekte machte die Bedeutung des Saales aus (wie in den vorbildlichen Antiquarien von München oder der unvollendeten Galerie des Schlosses Neugebäude), sondern das im Zusammenspiel der Ausstattung zum Ausdruck gebrachte Konzept. Die „Ahnenreihe“ der Habsburger erschien „durchdrungen“ von einer Reihe exemplarischer biblischer Figuren, die die Königsfigur als Vergleichsfolie heranzogen, vor allem aber eine Typologie beschworen, bei der der strafende Gott, der starke Führer sowie die Bedeutung des Priestertums thematisiert wurden. Mit dem Herbeizitieren der Sibyllen als humanistischem Äquivalent zu den Propheten suggerierte das Gesamtkonzept von Architektur, Skulptur und Malerei eine Idee von „Erfüllung“: In der Herrschaft der Habsburger - expressis verbis: Leopolds - erfüllten sich die Prophezeiungen einer universalen Herrschaft, da der Kaiser in sich die verschiedenen Qualitäten der Führerpersönlichkeiten des Alten Bundes ebenso vereinte wie die Ergebung in den Willen Gottes.

Abschließend lässt sich sagen: Scheint das Konzept der Galleria maior auf den ersten Blick eher kosmologischen Anforderungen zu gehorchen (mit den Kontinenten und Jahreszeiten in den Skulpturen), äußert sich die unzweifelhaft politische Aussage erst (!) durch eine gemalte Bilderfolge, in der sich die untrennbare Vereinigung politischen und geistlichen Anspruchs manifestierte. Der technische Sonderfall, dass auf eine geglättete Putzfläche sekundär (und letztendlich erfolglos) Malerei aufgetragen wurde, lässt sogar den hypothetischen Schluss zu, dass die Idee einer malerischen 
Gestaltung überhaupt erst nachträglich und zur Verdeutlichung eines Sinngehalts entstanden war, den man in den Skulpturen zu wenig scharf formuliert sah. Denn es ist klar: Die in Nischen aufgestellten Figuren hätten in ihrer Isoliertheit nicht jene zwingende Logik entfaltet, die ihnen durch die narrativen Schilderungen der Deckenbilder ermöglicht wurde. In diesem „Vertrauen“ in die medialen Möglichkeiten der Wandmalerei kündigt sich jenes Phänomen an, das zu den Großdekorationen des 18. Jahrhunderts und ihrem concettismo führen sollte.

\section{Vergleich: Der Türkensaal des Stiftes Altenburg, um 1689}

Vielleicht ist in den als Fresken ausgeführten, seitlichen Bildfeldern der Galleria maior - die somit zeitlich nach den mittleren Seccogemälden anzusetzen wären - ein erster Versuch einer Renovierung der Gemälde festzumachen. Das würde erklären, warum der Raum so rasch aufgegeben wurde und in der großen Beschreibung des Stiftes Zwettl von 1725 gerade einmal des Eintrags ein großer Saal wert war. ${ }^{22}$ Die bis heute sichtbaren Schäden an der Malerei der Mittelfelder - im Unterschied zu den makellos erhaltenen Freskokartuschen über den Fenstern - dürften alten Ursprungs sein: Die Malerei erwies sich als zu spannungsreich im Vergleich zum geglätteten (ungrundierten?) Untergrund, bildete starke Schollen und platzte an vielen Stellen von der Decke ab. ${ }^{23}$ Der riesige Saal entpuppte sich im Prozess seiner Erhaltung somit schon bald als permanenter konservatorischer Problemfall. Der sichtbare Firnisüberzug, der auf den zentralen Temperabildern festzustellen ist, wäre unter diesem Gesichtspunkt als der unzulängliche Versuch zu deuten, die allzu spannungsreich aufgetragene Malschicht zu sichern und am Abblättern zu hindern. Es wäre verlockend, die Beschäftigung des Malers Jacob Pink, ${ }^{24}$ der 1706/1707 mit immerhin $101 \mathrm{fl}$. als Maller entlohnt wurde, mit einer solchen kleinen Instandsetzung in Verbindung zu bringen - und in ihm zugleich den Meister der kleinen Ergänzungen im Fresko zu sehen. ${ }^{25}$

Tatsächlich war dem Modell einer Secco-Malerei auf Putz keine große Nachfolge beschieden. Schon die wohl nur ein Jahrzehnt später entstandenen Malereien des sogenannten Türkensaals im Benediktinerstift Altenburg, ${ }^{26}$ vierzig Kilometer von Zwettl entfernt, zeigen eine veränderte Erwartungshaltung hinsichtlich der gemalten Dekoration. Obwohl hier ebenfalls der Typus der Galerie gewählt wurde, präsentiert sich die hervorragend erhaltene Malerei in einem wesentlich fortschrittlicheren Gestus: Scheinarchitekturen und Elemente des stucco finto gliedern den kompletten Saal, der gänzlich auf plastische Elemente verzichtet (Abb. 8). War schon der Anlass zur Erstellung der Malerei ein profan-politischer (das zentrale Thema des Raumes ist die Rückeroberung von Nissa im Herbst 1689; Abb. 9), legt der Blick auf das Konzept des Saales ein gänzliches Fehlen religiöser Aussagen frei. Die Verherrlichung des siegreichen „Türken-Luis“, des Herzogs Ludwig von Baden-Baden, bietet den Anlass, dem Sieger über die Osmanen und dem Habsburgerkaiser

22 Stiftsarchiv Zwettl, StiAZ 3/32, olim Handschrift 126a-b.

23 Da sich auf den 1778 eingezogenen Holzgewölben keine Schollen finden, müssen die Schäden älter sein.

24 Pavel PREISS, ... pictor Kraloviti ... natus Austriac. Windichstadiensis ... Der Maler Jakob Anton Pink - ein Waldviertler im Dienst der Zisterzienser in Böhmen, Reiselust \& Kunstgenuss. Barockes Böhmen, Mähren und Österreich (Hrsg. Friedrich Polleroß), Petersberg 2004, S. 119-124.

25 Stiftsarchiv Zwettl, StiAZ Kammeramt 1, Kammeramt Rapular 1706 (7. Juli ff.). Eine Beschäftigung Pinks mit der Freskomalerei wäre auch hinsichtlich des in Lilienfeld dokumentierten „Jacob Pianck“ interessant.

26 EGGER 1983 (Anm. 17), S. 1-7. 


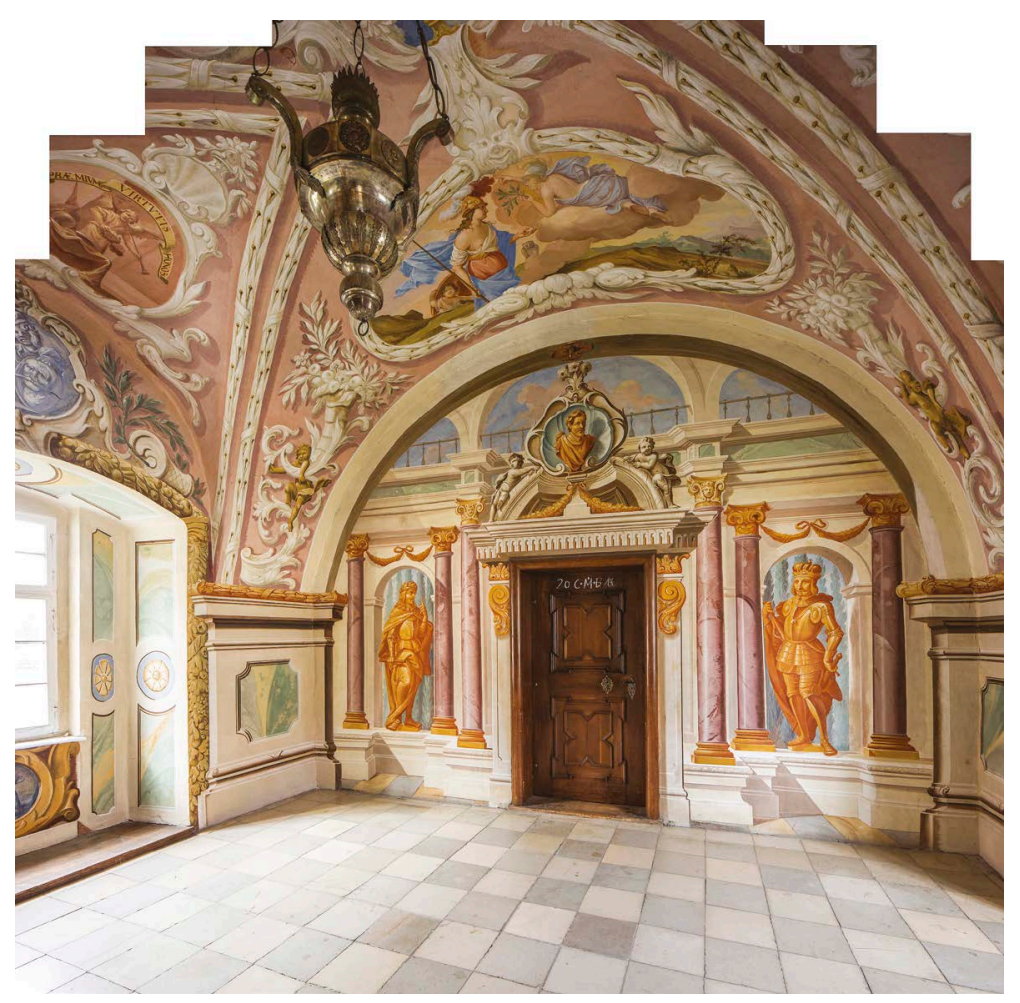

8. Einblick in den Westteil des sogen. Türkensaals, um 1689, Stift Altenburg

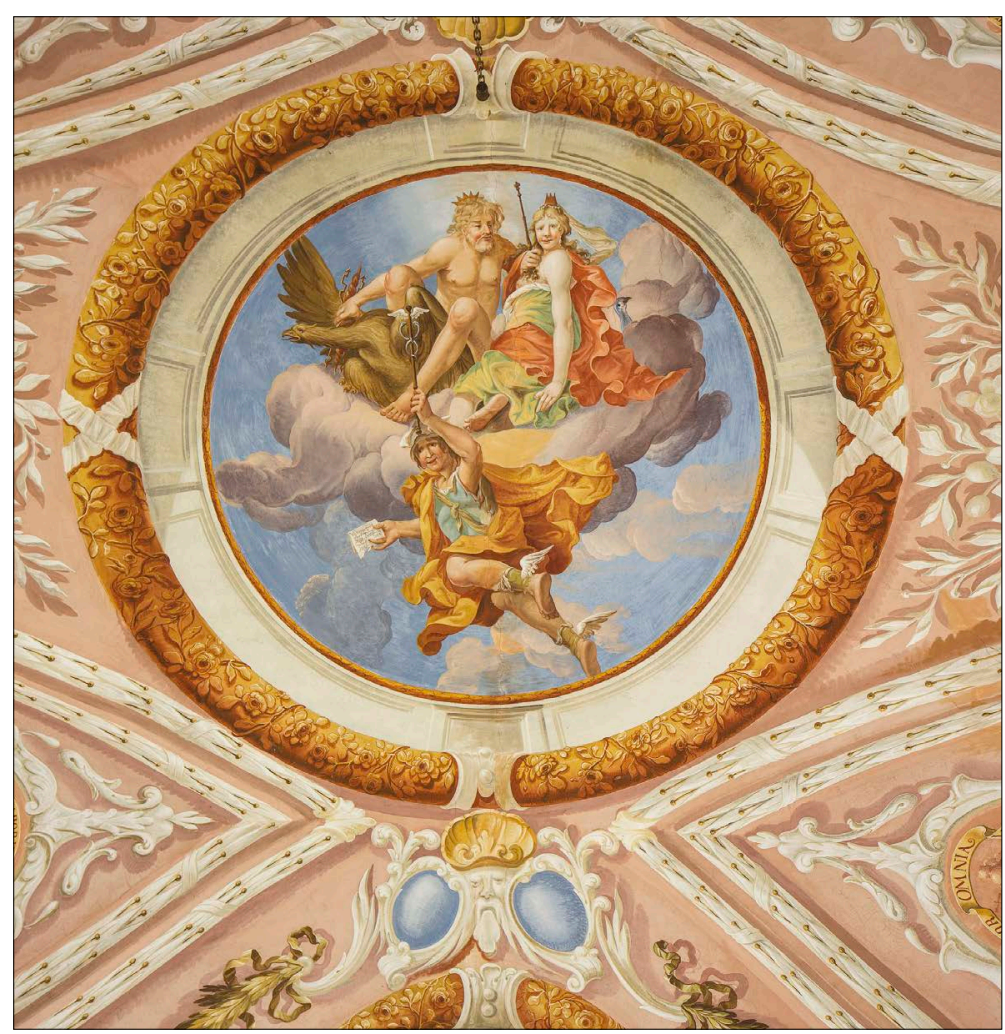

9. Unbekannter Meister: Merkur überbringt die Nachricht vom Sieg bei Nissa, um 1689, Türkensaal, Stift Altenburg 
Leopold die Ehre zu erweisen, das hierbei zum Einsatz gekommene Figurenrepertoire verzichtete aber mit Jupiter, Merkur, Juno oder Minerva völlig auf einen, wie man sagen möchte, dem Kloster angemessenen Wortschatz.

Die Frische der Malerei, im Gegensatz zu den gedeckten Gemälden Fabers in der Zwettler Galleria maior, macht die rasche Entwicklung des Mediums Wandmalerei deutlich. Der Illusionswert beginnt zu wachsen, die rahmenden Systeme werden nicht mehr dreidimensional ausgeführt, sondern durch das Geschick des Malers vorgetäuscht. Obwohl auch die Altenburger Galleria viele Elemente des Additiven und Rustikalen bietet, stellt sie dennoch das Potential unter Beweis, das in den letzten Jahrzehnten des 17. Jahrhunderts auch an der Peripherie bezüglich der Monumentalmalerei vorhanden war. Ihre Bedeutung sollten die provinziellen Initialwerke dennoch bereits im 18. Jahrhundert angesichts der Leistungen modernerer Maler einbüßen, die - wie Rottmayr, Gran oder Troger - über internationale Ausbildung und Kenntnis verfügten.

\section{Nachsatz: Die Zerstörung der Galleria maior, 1777/1778}

Der Galleria war kein einfaches Schicksal beschieden. Hatte sich schon ihre Errichtung vor dem Hintergrund der Pestepidemie von 1679 abgespielt, der 1683 die Flucht eines Großteils des Konventes vor den Türken folgen sollte (die im Archiv erhaltenen Reisepässe der Konventualen sind eindrucksvolle Zeugnisse der Drastik der Situation), machten Unzulänglichkeiten in der Ausführung und möglicherweise schon bald zutage tretende Schäden an den Malereien den Saal zur ungeliebten Dauerbaustelle. Fünfzig Jahre nach Fertigstellung wurde er schließlich durch Einbau von kleineren Räumen unterteilt, wobei bis 1778 der Mittelteil als (mehr oder weniger unansehnliches) Raumfragment Bestand hatte. Erst in jenem Jahr, genau ein Jahrhundert nach seiner Errichtung, verschwand auch der letzte Rest des ambitionierten Unterfangens in den Zwischendecken der darunter neu eingezogenen Rokoko-Sommerzimmer. ${ }^{27}$

Gerade das Scheitern des Vorhabens macht aber auch die Bedeutung des Saales und seiner Dekoration aus. Die unberührte Authentizität des Ensembles konfrontiert den Betrachter mit einer verblüffenden Qualität, zu der auch die originelle Expressivität zu rechnen ist. Mit einem erstaunlichen Grad an Experimentierfreude, vor allem nämlich im technologischen Bereich, manifestiert sich eine noch unroutinierte Gestaltungspraxis, die (wenig erfolgreich) versuchte, Möglichkeiten der Tafelmalerei auf die Wandmalerei zu übertragen. Die mediale Intention der Dekoration ist dabei noch weit entfernt vom „Selbstbewusstsein“, das wenige Dekaden später die Barockkunst prägen sollte. Nicht nur technisch, auch im Umgang mit den Möglichkeiten der Perspektive fehlt vollkommen der Wille zur Überwältigung auf Basis visueller Mittel. Die Argumentationskraft liegt hier noch im „Was“, nicht im „Wie“ der Darstellung.

Obwohl sich in der Kombination von Skulptur und Malerei (und in letzter Konsequenz auch durch die eindrucksvolle Monumentalität der Architektur) eine Form von sprachlichem Potential eröffnete, sind viele Wirkmittel der spät- und spätestbarocken Malerei noch ausgespart: Ja, es gibt Sinnbezüge zwischen den Statuen in den Pfeilern und den Protagonisten der Bildfelder. Die Gemälde legitimieren durch ihre Erzählung die Aufstellung der Skulpturen und entwerfen die Idee

27 Andreas GAMERITH, Al fresco! Die Wandmalerei in Österreich zur Zeit Maria Theresias, Maria Theresia und die Kunst (Hrsg. Stella Rollig, Georg Lechner), Belvedere, Wien, München 2017, S. 128-129. 
eines übergeordneten Konzepts. Aber: Die Aussagekraft wird nicht durch eine mediale Verfasstheit der Bilder erzielt. Ob die Erzählungen durch Stuckreliefs, eingesetzte Ölbilder oder al fresco vorgestellt würden, spielte hier noch keine Rolle. Es gab demzufolge keine definierten „idealen Standpunkte“, der Figurenmaßstab ist unterlebensgroß, Bild und Raum stehen in keinem direkten Verhältnis zueinander. Auch die Leserichtung der Bildfelder ist gerade ansatzweise didaktisch komponiert und gehorcht einer „dekorativen Logik“, die den Betrachter am ehesten „flanierend“ sieht. Obwohl die Galleria Maior zum Zeitpunkt ihrer Entstehung definitiv das ambitionierteste Projekt der Zwettler Klosterumgestaltung darstellte (das zudem den Vergleich mit internationalen Prestigebauten nicht scheute), blieben die zum Einsatz gebrachten Wirkmittel auf dem Niveau der herkömmlichen Malereipraxis. Das Ergebnis, gerade auch im fragmentierten wie reduzierten Zustand, zählt dennoch zu den reizvollen Randerscheinungen einer Entwicklung, die schon bald völlig neue Wege beschreiten sollte. 


\section{Bibliographie}

ANDRASCHEK-HOLZER, Ralph, Altenburg und Zwettl. Ansichten zweier Klöster, Das Waldviertel, 64/3, 2015, S. 205-225.

BUBERL, Paul, Die Kunstdenkmäler des Zisterzienserklosters Zwettl, Wien 1940 (Ostmärkische Kunsttopographie, 29).

COURTIN, Nicolas, Les grandes galeries européennes. XVIIe-XIXe siècle, Bulletin Monumental, 171/1, 2013, S. 80-81.

Deckenmalerei um 1700 in Europa. Höfe und Residenzen (Hrsg. Stephan Hoppe, Heiko Laß, Herbert Karner), München 2020.

EGGER, Hanna, Der Triumph der Gerechtigkeit, der Tapferkeit und der Liebe. Zur Ausstattung der Trakte des 17. Jahrhunderts um den Prälaturhof des Stiftes Altenburg, Alte und moderne Kunst, 28/189, 1983, S. 1-7.

GAMERITH, Andreas, Al fresco! Die Wandmalerei in Österreich zur Zeit Maria Theresias, Maria Theresia und die Kunst (Hrsg. Stella Rollig, Georg Lechner), Belvedere, Wien, München 2017, S. 117-147.

GRETZEL, Doris, CHIBA, Bertram, Hinter Mauern und Zäunen. Die Gärten des Stiftes Zwettl, Zwettl 2006 (Zwettler Zeitzeichen, 11).

KAPEUNDL, Christina, Georg Kurz und die frühbarocken Gemälde für die Stiftskirche Zwettl, Wien 2012 (unpublizierte Diplomarbeit).

KUBES, Karl, Frühbarocke Architektur und Kunst, Stift Zwettl und seine Kunstschätze (Hrsg. Karl Kubes, Joachim Rössl), St. Pölten-Wien 1979, S. 76-82.

MÖSENEDER, Karl, Deckenmalerei, Barock (Hrsg. Hellmut Lorenz), München-London-New York 1999 (Geschichte der bildenden Kunst in Österreich, 4), S. 303-318.

POLLEROSS, Friedrich, Imperiale Repräsentation in Klosterresidenzen und Kaisersälen, Alte und moderne Kunst, 30/203, 1985, S. 17-27.

PREISS, Pavel, ... pictor Kralovitii ... natus Austriac. Windichstadiensis ... Der Maler Jakob Anton Pink - ein Waldviertler im Dienst der Zisterzienser in Böhmen, Reiselust \& Kunstgenuss. Barockes Böhmen, Mähren und Österreich (Hrsg. Friedrich Polleroß), Petersberg 2004, S. 119-124.

RIEWEL, Hermann von, Neue Funde im Stifte Zwettl 1893, Mittheilungen der $k$. $k$. Central-Commission zur Erforschung und Erhaltung der Kunst- und historischen Denkmale, n. F. 21, 1895, S. 87-90.

SCHEMPER, Ingeborg, Stuckdekorationen des 17. Jahrhunderts im Wiener Raum, Wien-Köln 1983 (Dissertationen zur Kunstgeschichte, 17).

STRUNCK, Christina, Die Galerie in der Literatur. Historische Quellen zur Definition, architektonischen Gestalt, idealen Ausstattung und Funktion von Galerien, Europäische Galeriebauten. Galleries in a Comparative European Perspective (1400-1800). Akten des Internationalen Symposiums der Bibliotheca Hertziana, Rom, 23.-26. Februar 2005 (Hrsg. Christina Strunck, Elisabeth Kieven), München 2010, S. 9-32.

WEISS, Petra, „Denkmäler sind häufig Flickenteppiche...“. Geschichte der Kirchenrestaurierung, Zisterzienserstift Zwettl. Die Restaurierungsgeschichte (Hrsg. Franz Romeder), St. Pölten-SalzburgWien 2013, S. 85.

WERNER, Jakob, Barocker Stuckdekor und seine Meister in Stift Altenburg, Benediktinerstift Altenburg 1144-1994. 850 Jahre Benediktinerstift Altenburg (Hrsg. Ralph Andraschek-Holzer) St. Ottilien 1994 (Studien und Mitteilungen zur Geschichte des Benediktinerordens und seiner Zweige, Ergänzungsband 35), S. 293-328. 
ZEIT DES EXPERIMENTS. DIE GALLERIA MAIOR DES STIFTES ZWETTL ALS BEISPIEL FÜR SEICENTESKE WANDMALEREI IN NIEDERÖSTERREICH

\section{Abbildingsnachweis}

1: Mittheilungen der $k$. $k$. Central-Commission zur Erforschung und Erhaltung der Kunst- und historischen Denkmale, n. F. 21, 1895.

2-9: Andreas Gamerith. 


\section{Čas eksperimentiranja \\ Galleria maior v samostanu Zwettl kot primer stenskega slikarstva \\ 17. stoletja v Spodnji Avstriji}

Povzetek

Samostani v deželi okoli Dunaja so v 18. stoletju bistveno prispevali k razcvetu srednjeevropskega monumentalnega slikarstva: $\mathrm{v}$ njih je bilo izvedenih več velikih projektov kakor $\mathrm{v}$ plemiškem okolju, mojstrsko pa so jih uresničevali vodilni umetniki. Predhodniki te faze, ki je pomenila vrhunec nekega razvoja, so bile vsekakor posamezne ambiciozne poslikave 17. stoletja, katerih eksperimentalni značaj se kaže tako v njihovi programski zasnovi kakor tudi v tehnični izvedbi.

Galleria maior v samostanu Zwettl predstavlja med temi poslikavami posebej zanimiv primer. Notranjščina galerije, zasnovane kot monumentalna, 51 metrov dolga dvorana, je bila v letih 1679-1681 razkošno opremljena. Dunajski štukater Domenico Piazoll je na oboku izvedel močne štukature, ki tvorijo okvirje za stropne slike, delo nürnberškega slikarja Sebastiana Fabra. V niše med okni so postavili kipe, po konceptu povezane s slikami. V srednji osi je bila dvorani priključena umetna grotta z inkrustiranimi školjkami.

Koncept prostora je združeval elemente poveličevanja vladarske hiše s poudarjanjem lastne identitete samostana kot religiozne institucije - kozmologijo, katere harmonija naj bi temeljila na vzajemnem delovanju Države in Cerkve. Medtem ko so predstavljale figure v nišah kontinente in letne čase, so bili štiri sibile in štirje predstavniki Stare zaveze - Mojzes, Aron, David in Noe - vključeni kot primeri Božjega razodetja od začetka sveta. Stropne slikarije, serija različno velikih medaljonov, so kazale po eni strani različne vladarje od začetka sveta (na koncu je bil upodobljen takratni cesar Leopold I.), po drugi pa svetopisemske prizore v devetdelnem ciklu, ki je delno uničen. Od sredine proti jugu so si sledili prizori Adam poimenuje živali, Noetova molitev pred barko, Vesoljni potop, Noetova zahvalna daritev (?) in Abraham in trije angeli (?). Proti severu so bili naslikani prizori iz Mojzesove zgodbe: Mojzes pred faraonom, Žabja nadloga, Faraonov potop v Rdečem morju in - morda - Mojzesova zahvalna molitev. Vsebinsko lahko vse prizore povežemo v smislu »pokornosti Božjim zapovedim« kot tudi »kazni zaradi nepokorščine«; prominentna vloga duhovnika Arona v prizorih iz Mojzesove zgodbe pa nas prepričuje o velikem pomen duhovščine pri vodenju Božjega ljudstva.

Tehnično izvedbo stropnih slik $\mathrm{v}$ Zwettlu moramo oceniti kot izjemno posebnost $\mathrm{v}$ zgodovinskem razvoju, saj so bile naslikane v temperi al secco, le mali emblemi so bili (sekundarno?) dodani al fresco. Nanesena na zglajene ploskve ometa, pa se je barvna plast hitro izkazala za preveč napeto in se začela luščiti v grudah. Videti je, da so poskušali slike restavrirati tako, da so jih premazali s firnežem, vendar neuspešno, najpozneje $\mathrm{v}$ dvajsetih letih 18. stoletja pa so dele dvorane pregradili. V letih 1777/78 so zadnji ostanki dekoracije iz 17. stoletja izginili za vmesnimi stropi novih rokokojskih poletnih sob, kjer so jih ponovno odkrili šele leta 1893. Spodleteli poskus v Zwettlu, ki se je začel kot velik prestižen projekt in so ga po dolgoletnih popravilih nazadnje opustili, ponazarja nelinearni razvoj, ki je v poznem 17. stoletju pripravljal pot za mojstrovine 18. stoletja, uvrščene med briljantne dosežke poznega baroka. 